\title{
1 Albedo and LAI estimates from FORMOSAT-2 data for crop
}

\section{2 monitoring}

3

4

5

Aline Bsaibes *a,b ${ }^{\text {a, Dominique Courault }}{ }^{\text {a,b }}$, Frédéric Baret ${ }^{\text {a,b }}$, Marie Weiss ${ }^{\text {a,b }}$, Albert Olioso ${ }^{\text {a,b }}$, Frédéric Jacob ${ }^{c}$, Olivier Hagolle ${ }^{\mathrm{d}}$, Olivier Marloie ${ }^{\mathrm{a}, \mathrm{b}}$, Nadine Bertrand ${ }^{\mathrm{a}, \mathrm{b}}$, Véronique Desfond $^{\text {a,b }}$, Farzaneh Kzemipour ${ }^{\text {a,b }}$.

a INRA, UMR1114, EMMAH, Domaine Saint-Paul, Site Agroparc, F-84914 Avignon, France

${ }^{\text {b }}$ Université d'Avignon, UMR 1114, EMMAH, Domaine Saint-Paul, Site Agroparc, F-84914 Avignon, France

c IRD, UMR LISAH, 2 Place Viala, 34060 Montpellier, France

${ }^{\text {d }}$ CNES, BPI 811, 18 av. E. Belin, 31401 Toulouse, France

\section{ABSTRACT}

This paper aimed at estimating albedo and Leaf Area Index (LAI) from FORMOSAT-2 satellite that offers a unique source of high spatial resolution (eight meters) images with a high revisit frequency (one to three days). It mainly consisted of assessing the FORMOSAT-2 spectral and directional configurations that are unusual, with a single off nadir viewing angle over four visible - near infra red wavebands. Images were collected over an agricultural region located in South Eastern France, with a three day frequency from the growing season to post-harvest. Simultaneously, numerous ground based measurements were performed over various crops such as wheat, meadow, rice and maize. Albedo and LAI were estimated using empirical approaches that have been widely used for usual directional and spectral configurations (i.e. multidirectional or single nadir viewing angle over visible - near infrared wavebands). Two methods devoted to albedo estimation were assessed, based on stepwise multiple regression and neural network (NNT). Although both methods gave satisfactory results, the NNT performed better (relative RMSE $=3.5 \%$ versus $7.3 \%$ ), especially for 
low vegetation covers over dark or wet soils that corresponded to albedo values lower than 0.20 .

Four approaches for LAI estimation were assessed. The first approach based on a stepwise multiple regression over reflectances had the worst performance (relative RMSE $=65 \%$ ), when compared to the equally performing NDVI based heuristic relationship and reflectance based NNT approach (relative RMSE $\approx 34 \%$ ). The NDVI based neural network approach had the best performance (relative RMSE $=27.5 \%$ ), due to the combination of NDVI efficient normalization properties and NNT flexibility. The high FORMOSAT-2 revisit frequency allowed next replicating the dynamics of albedo and LAI, and detecting to some extents cultural practices like vegetation cuts. It also allowed investigating possible relationships between albedo and LAI. The latter depicted specific trends according to vegetation types, and were very similar when derived from ground based data, remotely sensed observations or radiative transfer simulations. These relationships also depicted large albedo variabilities for low LAI values, which confirmed that estimating one variable from the other would yield poor performances for low vegetation cover with varying soil backgrounds. Finally, this empirical study demonstrated, in the context of exhaustively describing the spatiotemporal variability of surface properties, the potential synergy between 1) ground based web-sensors that continuously monitor specific biophysical variables over few locations, and 2) high spatial resolution satellite with high revisit frequencies.

\section{Introduction}

Several applications may exploit remote sensing estimates of land surface variables. They include agriculture, forestry or land management as well as hydrological and meteorological forecasts. Due to the high level of spatial heterogeneity, the size of agricultural fields or natural vegetation patches, and the large dynamic of vegetation, observations made frequently at high spatial resolution are desirable. However, because of technological and economical constraints, only high spatial 
resolution sensors (10-30 m) with low revisit frequency (15-30 days) or low spatial resolution (250$1000 \mathrm{~m}$ ) with high revisit frequency (between one and three days) have been available over the last three decades. With the continuous technological advances that reduce mass and cost of sensors and satellite platforms, new missions are planned or launched such as FORMOSAT-2 (Chern et al., 2006), Rapid-eye (Scherer and Kriscke 2001), Ven $\mu$ s (Dedieu et al., 2006) and Sentinel-2 (Martimort et al., 2007).

Among the several surface variables that are accessible from remote sensing observations, Leaf Area Index (LAI) and albedo are key players involved in the main processes that drive soil-plantatmosphere exchanges and biomass accumulation, including light and rain interception, evaporation and transpiration, as well as photosynthesis and respiration. These two variables are part of the essential climate variables identified by the Global Climate Observing system (GCOS, 2006). LAI is defined as half the developed leaf area per unit of horizontal ground area, where leaf area includes both leaf faces (Chen and Black 1992). Albedo is defined as the fraction of solar irradiance (diffuse and direct fractions) reflected by the surface in the upper hemisphere, and integrated over a given broad spectral domain (Jacob and Olioso 2005). For energy balance related applications, the integration domain is [0.3-3.0] $\mu \mathrm{m}$ to derive solar albedo, although this domain is often split for meteorological modeling into shortwave $([0.3-0.7] \mu \mathrm{m})$ and infrared $([0.7-3.0] \mu \mathrm{m})$ sub-domains, to derive visible and near-infrared albedos respectively. While surface albedo is partly influenced by LAI, several other variables have to be included for its computation, in addition to illumination conditions: canopy structure (leaf area density, vegetation height, clumping and orientation...), and leaf and soil optical properties (Jacobs and van Pul 1990; Olioso 1992; Weiss et al., 1999). For this reason no simple and general relationship between albedo and LAI is a priori expected.

Estimating LAI from remote sensing may be achieved using empirical relationships or radiative transfer model based algorithms, as recently reviewed by Baret and Buis (2008). Empirical 
relationships may either use bidirectional reflectance measurements along with parametric inverse models such as multiple linear regression (Eklundh et al., 2003) and neural networks (Baret et al., 1995), or combine bands into vegetation indices used as input for parametric modeling (Baret and Guyot, 1991; Walthall et al., 2004). Such approaches are limited by data dependence and therefore have a limited extrapolation capacity. Radiative transfer model inversion is potentially a very powerful approach (Goel, 1989, Weiss et al., 2000; Meroni et al., 2004; Schlerf and Atzberger, 2006; Darvishzadeh et al., 2008), able to explicitly account for available information such as known peculiarities of targeted canopies thanks to a priori knowledge. However, radiative transfer model inversion is often limited by the realism of canopies structure description, and is known to be severely ill-posed, which induces equifinality problems (Combal et al., 2002; Durbha et al., 2007).

Albedo can also be estimated from remote sensing by inverting radiative transfer models, but the difficulties are the same than those faced when retrieving LAI. Another possibility is using statistical relationships to perform a spectral extrapolation, so called Narrowband-To-Broadband (NTB) conversion. NTB conversion can be applied to nadir bidirectional reflectance (Brest and Goward, 1987; Russell et al., 1997; Liang et al., 1999; Song and Gao 1999; Liang, 2001; 2003; Liang et al., 2005; Susaki et al., 2007) or, more adequately, on hemispherical reflectance (Wanner et al., 1997; Weiss et al., 1999; Jacob et al., 2002a; van Leeuwen and Roujan, 2002; Greuell and Oerlemans, 2004), where the latter is derived from Bidirectional Reflectance Distribution Function (BDRF) parametric modeling along with directional integration over the upper hemisphere (Lucht, 1998; Lucht and Roujean, 2000; Jacob et al. 2002b; Pokrovsky and Roujean, 2003). Although proved efficient when the directional dimension is sufficiently sampled, BRDF modeling can not be applied to sensors such as FORMOSAT-2 or Ven $\mu$ s because the latter have single viewing configurations. Besides, applying NTB conversion to FORMOSAT-2 or Sentinel data is not straightforward regarding limited spectral samplings but especially single off nadir viewing angles. Indeed, NTB conversion has been widely used for multidirectional observations or single nadir 
viewing directions as abovementioned, but never for single off nadir viewing angles.

In the context of the high spatial resolution and revisit frequency offered by the FORMOSAT-2

107 sensor, the objective of this study was to explore its potentialities for the retrieval of solar albedo

108 and LAI, regarding the specificities of its spectral and directional configurations. Rather than

109 elaborating complex approaches based on radiative transfer model inversion, we concentrated on

110 empirical approaches based on continuous ground measurements over few representative fields.

111 Remote sensing and ground based datasets were collected over the Crau-Camargue experimental

112 site. The latter embraced a wide range of vegetation and soil moisture conditions, from dry wheat

113 and bare soil fields to irrigated meadow and flooded rice plantations. This allowed investigating the

114 robustness of the empirical methods considered for albedo and LAI retrieval. Furthermore, the high

115 revisit frequency of the collected FORMOSAT-2 dataset provided unique and detailed information

116 about evolution of land surface variables, over a large period ranging from the growing season to

117 post-harvest of major crops. From these chronicles of spatialized measurements, it was therefore

118 interesting to characterize the dynamics of albedo and LAI over different crop cycles, to analyze

119 possible links between these two variables, and to detect possible characteristic trends for different

120 vegetation covers according to anthropogenic forcing such as agricultural practices.

122 The paper is structured as follows. Section 2 describes the experiment and the resulting data set.

123 Section 3 presents the empirical methods developed to retrieve albedo and LAI from FORMOSAT-

1242 data. Section 4 provides the performances of albedo and LAI retrieval methods, and discusses the

125 temporal dynamics of both variables for the several crops we considered. The best performing

126 methods for albedo and LAI retrieval are next selected and applied to the whole image set. This

127 allows analyzing the possible relationships between albedo and LAI for several crops throughout

128 their cultural cycles. Finally, conclusions are drawn with due attention to potential applications and

129 need for further investigations. 


\section{$131 \quad 2$ Materials}

\section{$132 \quad 2.1$ The Crau-Camargue experimental site}

133

134 The study area was located in the "Crau-Camargue" area, South Eastern France $\left(43.53^{\circ} \mathrm{N} ; 4.66^{\circ} \mathrm{E}\right.$;

$1353 \mathrm{~m}$ above sea level, see Figure 1). Climate was typically Mediterranean, with irregular 136 precipitations, long dry periods in spring and summer, and strong winds. This flat area was 137 characterized by a wide range of soil and irrigation practices. The experiment took place in 2006 , 138 including intensive ground measurements simultaneously collected with satellite data on various 139 crop types (Courault et al., 2008). Low cumulative precipitation was observed in 2006 (456 mm) as 140 compared to the regional average (548 $\mathrm{mm}$ in 2005). The weather was especially dry from April $1^{\text {st }}$ 141 to mid-September, with one rainfall event only occurring in early June (28 $\mathrm{mm})$.
[Figure 1]
The land cover was classified using a maximum likelihood supervised classification. The latter relied on 1/ the four FORMOSAT-2 wavebands, 2/ five images distributed along the experimental period, and 3/ reference areas of known field occupation within the study area. Image number and repartition was driven by the temporal dynamics of vegetation cover, especially that resulting from anthropogenic forcing such as meadow cuts throughout the cultural cycle (three to four cuts per season, leaving $10 \mathrm{~cm}$ vegetation height). Twelve classes were identified, which included the main vegetation covers, free water and bare soil surfaces. Although this map was improved with ground based information, it was undeniably subject to uncertainties, with a $20 \%$ training residual error. Figure 1 displays the major vegetation classes that represented about $40 \%$ of the whole study area. 
154 The remaining $60 \%$ included natural marshlands, the Rhone River and other minor cultures.

\subsection{The five sampled fields}

157

158 Five fields that corresponded to the major crops within the region of interest (Figure 1) were chosen 159

for intensive ground based measurements. The two wheat fields (\#1 and \#2) were sown on November $11^{\text {th }}$ and December $15^{\text {th }}$, and harvested on June $27^{\text {th }}$ and July $4^{\text {th }}$, respectively. They were not irrigated, and turned to bare soils after harvest around DOY 179 ( $28^{\text {th }}$ of June). The meadow field (\#3) was flooded every 11 days according to a regional water management designed for high yields and quality. Three cuts were performed during the growing season, on May $5^{\text {th }}$, July $7^{\text {th }}$, and August $11^{\text {th }}$. The maize field (\#4) was sown on May $5^{\text {th }}$, was intermittently irrigated by sprinklers depending on weather conditions, and was finally harvested on August $8^{\text {th }}$. This field was located on poor soils that were very stony at some locations, which induced large heterogeneities in vegetation cover that affected the representativeness of ground based measurements. The rice field (\#5) was sown on dry soil on April $27^{\text {th }}$, then continuously submerged from May $5^{\text {th }}$ till October $6^{\text {th }}$ with a $0.10 \pm 0.05 \mathrm{~m}$ water height, and finally harvested on October $18^{\text {th }}$. Due to stem lodging within the rice field after August $30^{\text {th }}$ caused by strong winds, LAI measurements and FORMOSAT-2 reflectances were biased. Therefore, the data collected afterwards were discarded from analysis.

\subsection{Ground based measurements}

Albedo was measured with Kipp \& Zonen CM7 sensors mounted between $1.5 \mathrm{~m}$ and $2 \mathrm{~m}$ above top of canopy. Measurements were averaged over 10 minute periods throughout vegetation cycles. The measurement footprints were circular, with radii between 25 and $35 \mathrm{~m}$. Albedometers were calibrated to measure incoming radiation over the whole solar spectrum (300 to $3000 \mathrm{~nm})$. 
180 Leaf Area Index (LAI) was derived from hemispherical images that provided Effective LAI. The

181 latter was closer to remote sensing estimates than the true LAI because of leaf clumping (Weiss

182 et al., 2004). The hemispherical images were collected with time intervals of about 10 days, for

183 capturing canopy structure dynamics. In order to represent field average LAI, a cross-pattern

184 sampling protocol was adopted. It consisted of 50 hemispherical images acquired within each study

185 field at each date of measurement. Table 1 gives the main characteristics of the ground

186 measurements performed within the different above mentioned fields.

187

188

189

190

191

192

193

194

195

196

197

198

199
[Table 1]

The CAN-EYE software (http://www.avignon.inra.fr/can_eye/page5.php) was used to process the hemispherical images. CAN-EYE allowed computing the gap fraction from a series of RGB color images through a simple interactive supervised classification process. LAI was then derived from the resulting gap fractions, using look-up-table techniques based on the Poisson model (Nilson, 1971). A strong correlation $\left(\mathrm{R}^{2}=0.98\right)$ was observed when comparing those estimates against planimetry based destructive LAI measurements that were simultaneously collected over few locations. However a systematic underestimation of LAI due to leaf clumping was observed, with a clumping coefficient of 0.68 . This was consistent with the study from Demarez et al. (2008) who reported a value of 0.71 over wheat, maize and sunflower.

\subsection{FORMOSAT-2 Data}

FORMOSAT-2 is a high spatial resolution satellite that collects images with an $8 \mathrm{~m}$ nadir spatial resolution over a $24 \mathrm{~km}$ swath, in four $90 \mathrm{~nm}$ width wavebands centered at 488, 555, 650 and 
$830 \mathrm{~nm}$. The orbital cycle is completed within one day. The sensor may deviate from nadir in order to point at sites close to the ground track. Therefore, accessible locations at Earth's surface are observed under a unique viewing direction. In our case, the Crau-Camargue site was targeted with zenith (relative to nadir) and azimuth (relative to north) viewing angles around $41^{\circ}$ and $239^{\circ}$, respectively. Images were collected every three to four days at 10:30 UTC from March to October 2006. They were processed for geolocation, radiometric calibration and atmospheric perturbations following Hagolle et al. (2008). Clouds and related shadows were discarded following Baillarin et al. (2004). Over the 36 images collected between March and October, 30 images were cloudless, with a temporal gap spanning from April $17^{\text {th }}$ to May $14^{\text {th }}$ because of cloudy conditions.

\subsection{Matching ground measurements with FORMOSAT-2 data}

To consistently calibrate and validate the empirical methods we considered; it was necessary performing spatial and temporal matching between ground based and FORMOSAT-2 data.

For albedo, the four FORMOSAT-2 pixels included in each albedometer footprint were extracted and averaged. Albedo values acquired at 10:30 UTC were selected for comparisons, since they matched satellite overpasses. According to the starting and ending dates of data collection that varied from one field to another, the resulting dataset included 130 ground samples. Table 1 shows very low values for the albedo coefficient of variation $(\mathrm{CV}$, equal to the ratio of standard deviation to mean value) derived from FORMOSAT-2 retrievals (retrieving method explained in Section 3) over the albedometer footprints. Albedo could therefore be considered quite homogeneous, even for the maize field that depicted an albedo CV twice larger than those depicted by the other fields.

For LAI, ground based measurements and FORMOSAT-2 pixels were collected or selected in order 
to consider representative values at the field scale. Ground samples were collected within each field according to a cross-pattern protocol, and next averaged. For each field, FORMOSAT-2 overlaying

231 pixels were selected by excluding borders, and the corresponding waveband reflectances were 232 averaged. Table 1 shows the LAI CV over the field extensions, derived from FORMOSAT-2 233 retrievals on a pixel basis (retrieving methods explained in Section 3). The low LAI CV values for

234 the wheat, meadow and rice fields confirmed that comparing ground based and satellite data was consistent. However, the LAI CV for the maize field was significantly larger than those for the other fields, due to large heterogeneities for soil properties (Section 2.1.2). Calibration and validation results for this field were therefore carefully analyzed (Section 4 and 5). Overall, because of low heterogeneities for four fields over the fives, we expected calibration and validation results would not be affected by non linearity between LAI and reflectance values (Garrigues et al., 2007).

The quite low 10 day frequency of LAI ground based measurements induced a temporal interpolation was necessary, in order to obtain concurrent ground and satellite LAI estimates. For this purpose, the LAI dynamic model proposed by Koetz et al. (2005) was applied:

$$
L A I=k \cdot\left[\frac{1}{1+e^{-b(T-T i)}}-e^{-a(T-T S)}\right]
$$

$\mathrm{T}$ is the cumulated daily mean air temperature above vegetation zero, starting from the sowing date.

246 The growth period is defined by a logistic equation which parameter $b$ is the relative growth rate at the inflexion point $T_{i}$. The senescence is determined by an exponential equation which parameter a is the relative growth rate at the cumulated temperature $T_{s}$ when all leaves are senescent. The $\mathrm{k}$ parameter is the maximal leaf area. These parameters were estimated using the simplex iterative optimization method (Nelder and Mead, 1965), with a 5\% residual calibration error. For irrigated 251 meadow, this empirical model did not allow representing the cuts. Therefore, a simple linear 252 interpolation was applied, benefiting from more frequent ground based data on this field. Figure 9 253 (later in the result section) illustrates LAI chronicles for the five fields. According to the starting 254 and ending dates of data collection that varied from one field to another, the resulting dataset 
included 72 ground based estimates that matched FORMOSAT-2 retrievals, completed with 25 data

256 for which the background was bare for sure, corresponding to LAI $=0$.

257

258 A summary on the available albedo and LAI ground measurement datasets is given in Table 2. It is 259 shown albedo values were within the range of usual values reported in the literature, for both bare 260 soil and vegetation cover conditions. Values for LAI were up to almost seven, which yielded us 261 expecting saturation problems when retrieving LAI from FORMOSAT-2 reflectances, especially 262 for these specific situations of large vegetation cover.

\section{Methods}

When choosing the methods to be implemented for the retrieval of albedo and LAI from FORMOSAT-2 data, we concentrated on empirical approaches based on continuous ground based measurements over few representative fields. The motivations for choosing empirical approaches were multiple. In the context of exhaustively describing the spatiotemporal variability of surface properties, the FORMOSAT-2 spatial and temporal configurations allowed assessing the potentials of synergy between 1 /ground based web-sensors that continuously monitor specific biophysical variables over few locations, and 2/ high revisit frequency and high spatial resolution satellite images. Second, although using deterministic approaches has more portability, it required first inversion strategies that face the ill-posed problem and related equifinality troubles. Finally, the FORMOSAT-2 spectral and especially directional configurations allowed enlarging the assessment of empirical approaches that have been widely used for usual configurations (i.e. nadir viewing). 
For albedo, the considered empirical approaches were the Narrowband-To-Broadband (NTB)

281 conversion and the NNT based method. NTB conversion has been widely used for recovering 282 albedo. NNT based method has been extensively employed for the retrieval of biophysical variables 283 (fraction cover, chlorophyll content...) as reviewed by Baret and Buis (2008), and was therefore considered as a candidate method for albedo retrieval. When dealing with LAI, we considered multiple linear regressions similar to NTB conversion and recently proposed by Eklundh et al. (2003) for application over forests. We also assessed NNT based methods that have been widely used for retrieving LAI. In this last case, we considered to ways for applying NNT, either from reflectances to LAI, or from NDVI to LAI given NDVI has efficient normalization properties.

\subsection{Stepwise multiple regression method}

For a given sun direction $\Omega_{\mathrm{s}}$, albedo a $\left(\Omega_{\mathrm{s}}\right)$ over a considered spectral range can be approximated as the weighed summation of hemispherical reflectances $\rho_{j}^{h}\left(\Omega_{s}\right)$ (Jacob and Olioso, 2005):

$$
a\left(\Omega_{s}\right)=\gamma_{0}\left(\Omega_{s}\right)+\sum_{j=1}^{n} \gamma_{j}\left(\Omega_{s}\right) \cdot \rho_{j}^{h}\left(\Omega_{s}\right)
$$

A specific spectral band amongst $\mathrm{n}$ is labeled $\mathrm{j}$. The weighting coefficients $\gamma_{\mathrm{j}}\left(\Omega_{\mathrm{s}}\right)$ may vary as a function of $\Omega_{\mathrm{s}}$, and have to be adjusted through stepwise multiple regressions. As explained in Introduction, hemispherical reflectances $\rho_{j}^{h}\left(\Omega_{s}\right)$ may be derived from multidirectional observations through the parametric modeling of BRDF. When observations are available in a single viewing direction only, several studies proposed directly applying Equation 2 on bidirectional reflectances $\rho_{j}\left(\Omega_{s}, \Omega_{o}\right)$, where the latter are collected with close nadir viewing:

$$
\alpha\left(\Omega_{s}\right)=\beta_{0}\left(\Omega_{s}\right)+\sum_{j=1}^{n} \beta_{j}\left(\Omega_{s}\right) \cdot \rho_{j}\left(\Omega_{s}, \Omega_{o}\right)
$$


302

303

304

This relies on assuming hemispherical and nadir bidirectional reflectances are linearly related, either because spatial variabilities do not significantly affect the ratio of nadir to hemispherical reflected radiances, or because it is possible considering a constant BRDF shape that is scaled to the observed bidirectional reflectance. This strong assumption was directly validated over a limited range of environmental conditions only (Russell et al., 1997; Weiss et al. 2002a; Schaaf et al. 2002). However, indirect validations were performed over a large range of environmental conditions, through the comparisons of albedo products derived from Equation 3 against reference estimates (Brest and Goward, 1987; Russell et al., 1997; Liang et al., 1999; Song and Gao 1999; Liang, 2001; Liang et al., 2002; Liang, 2003; Liang et al., 2005; Susaki et al., 2007). For the current study, the additional difficulty was using off nadir bidirectional reflectance (zenith and azimuth angles of $41^{\circ}$ and $239^{\circ}$, respectively), which yielded foreseeing NTB conversion may perform poorly.

The stepwise multiple linear regression method has been applied by several authors for different spectral and angular configurations. Given no coefficient set were available for the FORMOSAT specific configuration over the Crau-Camargue study site, we assessed the performances of a coefficient set calibrated over the collected dataset, and compared against existing coefficient sets proposed by Weiss et al. (1999), Liang et al. (1999), and Jacob et al. (2002a). These coefficients sets were obtained by considering different spectral configurations (waveband locations and widths), different directional configurations (using Equation 2 and 3 for hemispherical or nadir reflectances respectively), and by considering or not the diffuse component of solar irradiance.

LAI was derived from multiple linear regression applied over bidirectional reflectances by using the same formalism as Equation 3. As compared to Eklundh et al. (2003) who validated the concept with Landsat data over coniferous and deciduous forest canopies, assessing this approach was interesting with regards to the large differences in experimental conditions, whether it was the considered biomes (agricultural lands versus forests), the directional configuration (off nadir versus 
nadir viewing), or the spectral configuration (no shortwave infrared band with FORMOSAT-2).

330 For both LAI and albedo retrievals, we suspected a significant limitation when using the coefficient 331 set calibrated over the whole Crau-Camargue dataset, with regards to changes in solar direction at 332 the time of satellite overpass. Indeed, solar zenith (respectively azimuth) angle varied throughout 333 the experimental period from $25^{\circ}$ to $45^{\circ}$ (respectively from $135^{\circ}$ to $160^{\circ}$ ). Equation 3 was therefore 334 adjusted for each individual date, using the five pairs of matching ground albedo measurements / 335 FORMOSAT-2 bidirectional reflectances. Results displayed in Figure 2 showed that coefficients $336 \beta_{\mathrm{j}}\left(\Omega_{\mathrm{s}}\right)$ devoted to albedo did not exhibit specific features as a function of solar direction, indicating 337 these coefficients could be assumed independent on $\Omega_{\mathrm{s}}$. The same independency was observed for 338 the coefficients devoted to LAI (results not shown for sake of brevity). Therefore, $\beta$ coefficients were also assumed independent on $\Omega_{\mathrm{s}}$ for LAI in Equation 3.

\subsection{Neural network based method (NNT)}

Neural networks enabled relating the FORMOSAT-2 Green, Red and NIR waveband reflectances to either ground based albedo values or interpolated LAI (labeled $\mathrm{NNT}_{\mathrm{Ref}}$ ). The Blue waveband was omitted because it considerably degraded the performances of both albedo and LAI estimations vegetation conditions at the global scale, the inclusion of the Blue band does not significantly improve the vegetation characterization. We used the feed-forward back-propagation algorithm

351 detailed in Hagan and Menhaj (1994). It was made of made of a single hidden layer with two 352 tangent-sigmoid neurons, and one output layer with a single linear neuron (Figure 3). Prior to 
training, inputs and outputs were normalized by their minimum and maximum values. The learning

354 process was achieved using the Levenberg-Marquardt back-propagation method. Twenty random

355 initializations were tested and the one providing the best performance was selected. Implementing

356 the neural network required 11 coefficients to be tuned over the training data set (eight weights and

357 three biases, Figure 3a). Hyper specialization was not evaluated due to the lack of independent data.

358 It was however reduced by the minimal architecture selected for the network.

359

360

361

362

363

364

365

366

367

368

369

370

371

372

373

374

375

376

377

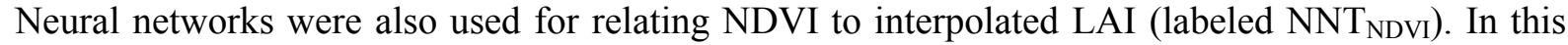
case, the implementation of the neural network required seven coefficients only to be tuned over the training data set (four weights and three biases, Figure 3b). Indeed, this implementation was based on a unique NDVI independent variable, whereas the previous NNT design was based on three independent variables as inputs, i.e. the Green, Red and NIR reflectances (Figure 3a).

\subsection{Exponential law based method}

Among the various relationships between NDVI and LAI proposed in the literature, we considered for the current study the exponential law derived from the studies of Asrar et al. (1984), Baret and Guyot (1991) and Wilson and Meyer (2007), and which has been widely used.

$$
L A I=-\left(\frac{1}{K_{L A I}}\right) \ln \left(\frac{N D V I-N D V I_{\infty}}{N D V I_{s}-N D V I_{\infty}}\right)
$$

$\mathrm{NDVI}_{\infty}$ is the asymptotic value of NDVI when LAI tends towards a maximum value, $\mathrm{NDVI}_{\mathrm{s}}$ is the bare soil NDVI value and $\mathrm{K}_{\mathrm{LAI}}$ is an extinction coefficient. The simplex optimization approach was used to adjust parameters $\mathrm{NDVI}_{\infty}, \mathrm{NDVI}_{\mathrm{s}}$, and $\mathrm{K}_{\mathrm{LAI}}$ by minimizing the Root Mean Square Error (RMSE) between measured and estimated LAI. 


\subsection{Calibration and validation procedures and performance metrics}

381 The experimental data set (sample number $\mathrm{N}=130$ for albedo and 97 for LAI) was not large enough 382 to be split into independent calibration and validation datasets. Therefore, a "leave-one-out" cross383 validation method (Stone 1974; Geisser 1975) was used for validation. It consisted in calibrating 384 over n-1 data, and validating over the remaining "left-out" data. This process was repeated $\mathrm{N}$ times 385 to cover the whole dataset. Then, performances were assessed using standards metrics:

- Absolute Mean Error $\left(\mathrm{ME}_{\mathrm{A}}\right)$, was the bias between measured $\left(\mathrm{M}_{\mathrm{i}}\right)$ and estimated $\left(\mathrm{E}_{\mathrm{i}}\right)$ values,

$$
M E_{A}=\frac{1}{n} \sum_{i=1}^{n}\left(E_{i}-M_{i}\right)
$$

- Absolute Root Mean Square Error $\left(\mathrm{RMSE}_{\mathrm{A}}\right)$ quantified the scatter between measured and estimated values, and Relative Root Mean Square error $\left(\mathrm{RMSE}_{\mathrm{R}}\right)$ was the ratio of $\mathrm{RMSE}_{\mathrm{A}}$ to the mean of measured values $\left\langle\mathrm{M}_{\mathrm{i}}\right\rangle$.

\subsection{LAl versus Albedo}

The large dataset of albedo and LAI, that included spatialized estimates spreading over entire crop cycles, allowed analyzing a possible relationship between these two biophysical variables. To be able to compare and understand such a possible relationship, radiative transfer simulations were carried out for conditions similar to those prevailing during the experiment. LAI and albedo values were simulated using the canopy reflectance model PROSAIL (Jacquemoud et al. 2008) for three types of ground surfaces (water, dry soil and wet soil), and a range of leaf inclination angles $\left(20^{\circ}\right.$, $40158^{\circ}$ and $70^{\circ}$ ) under a constant zenith angle of $30^{\circ}$. These values corresponded to averaged values 
402

403

404

405

406

407

408

409

410

411

412

413

414

415

416

417

418

419

420

421

422

423

424

425

that were representative of the experimental conditions. Diffuse fraction and spectral irradiance were simulated using the $6 \mathrm{~S}$ atmosphere radiative transfer model (Vermote et al., 1997) with midlatitude summer atmosphere and clear conditions (aerosol optical thickness at $550 \mathrm{~nm}$ set to 0.2347). All the other variables used for the simulations corresponded to typical average values representative of soil and vegetation conditions similar to the Crau-Camargue conditions (Table 3).

\section{Results and discussion}

[Table 3]

This section presents the results we obtained when retrieving albedo (§ 4.1) and LAI (§ 4.2), as well as when analyzing a possible relationship between both $(\S 4.3)$. For the retrieving of albedo and LAI, results are reported by separating method performances $(\S 4.1 .1$ for albedo, $\S 4.2 .1$ for reflectance based LAI, $\S 4.2 .2$ for NDVI based LAI) and analysis of chronicles captured by both ground based and FORMOSAT-2 observations ( $\$ 4.1 .2$ for albedo and $\S 4.2 .3$ for LAI).

\subsection{Albedo estimates from FORMOSAT-2 data}

\subsubsection{Comparison of the different method performances}

Table 4 displays the results we obtained for the retrieval of albedo, when calibrating NTB conversion and NNT method over the Crau-Camargue dataset (Set 1 and NNT), and when validating coefficient sets proposed by previous studies for other sensors with different spectral and direction configurations. Set 2 and 3 were calibrated over a simulated dataset, and designed for hemispherical reflectances collected within generic wavebands (Weiss et al., 1999). Set 4 was 
calibrated over a measured dataset, and designed for hemispherical reflectances collected within PolDER wavebands (Jacob et al., 2002a). Set 5 was calibrated over a measured dataset, and designed for nadir bidirectional reflectances collected within MISR waveband (Liang et al., 1999).

[Table 4]

The stepwise multiple regression (Equation 3) calibrated over the Crau-Camargue dataset was obtained by selecting positive and statistically significant bands only (Set 1). Best performances were obtained when using the Red and NIR bands only, with a corresponding offset equal to 0 . Thus, absolute bias $\mathrm{ME}_{\mathrm{A}}$ was almost negligible and Relative Root Mean Square Error $\mathrm{RMSE}_{\mathrm{R}}$ was acceptable, around $7.5 \%$. These validation results were comparable to calibration residual errors reported by Weiss et al. (1999), Liang et al. (1999) and Jacob et al. (2002a), and were close to relative accuracy of albedometer measurements and FORMOSAT-2 corrected data (around 5\%).

Similarities in performances for Set 1 versus Set 2 and 4 were explained by similarities in coefficient values, the latter varying of about 8 and $14 \%$ in relative for the red and near infrared bands, respectively. When applying coefficients Set 3 and 5 that included the Green band; performances were even worse as compared to Set 2 that included Red and NIR bands only. This indicated the Green band could have added more noise than information in albedo estimation.

We could not discriminate performances according to the consideration of hemispherical or nadir bidirectional reflectances, whereas the best performances were observed with the data set of FORMOSAT-2 off nadir bidirectional reflectance. These both elements contributed to strengthen the directional approximations formulated in Section 3.1, when assuming NTB conversion could also be applied to off nadir bidirectional reflectances. However, this positive report ought to be moderated because of additional complexities when comparing the different coefficient sets, such as 
the combined effects between differences in spectral configurations and land surface properties.

When dealing with the coefficient Set 1 that was calibrated over the Crau-Camargue dataset, the sum of the coefficients appeared to be almost equal to one (column $\Sigma \beta$ in Table 4). This was in agreement with Brest and Goward (1987), and Jacob et al. (2002a). Indeed, the whole solar spectrum could be split into nominal spectral intervals, and supposedly fully scanned through the corresponding wavebands. Then, the associated weighting coefficients corresponded to the fractions of solar irradiance over these intervals. However, this physical assumption might be far from reality when characterizing the whole spectral domain by using a visible and a near infrared band only. The Blue band was never significant in the considered coefficient sets: its weight might be relatively small due to the low radiation level. Further, it might also be considerably disturbed by residual atmospheric effects due to inappropriate aerosol corrections. Moreover, this band might not provide additional information. Indeed, Jiang et al. (2008) reported strong correlations with the Red band for a for a large range of vegetation conditions at the global scale.

Inspecting performances from one field to another showed that those were lower over rice and meadow, with $\mathrm{RMSE}_{\mathrm{R}}$ of $10.5 \%$ and $10.1 \%$ respectively. Figure $4 \mathrm{a}$ emphasizes the difficulties for the regression to fit the scattering induced by very different situations between meadow and rice, with an overestimation (respectively underestimation) for rice albedo (respectively freshly cut meadow albedo). These poor performances could be explained by the lack of water sensitive shortwave infrared (SWIR) wavebands within the FORMOSAT-2 configuration. Indeed, inclusion of such bands might improve albedo estimation under conditions of wet soil and free water background. To our knowledge, very few studies tried to estimate rice albedo from remote sensing, probably because of additional difficulties induced by the presence of water background. Very recently, Susaki et al. (2007) obtained a $\mathrm{RMSE}_{\mathrm{R}}$ of $15.1 \%$ with ASTER data over rice cultures in Japan, when applying the appropriate coefficient set proposed by Liang et al. (2001). This error was 
larger than that obtained here, indicating our calibrated coefficient set was acceptable, despite $1 /$ the consideration of complex surfaces that combined water and vegetation, 2/ the absence of FORMOSAT-2 SWIR waveband, and 3/ the consideration of off nadir bidirectional reflectances.

Table 4 also indicates the NNT method had the best performance. The improvement mainly occurred for meadow (RMSE $\mathrm{R}_{\mathrm{R}}$ decreasing from $10.3 \%$ to $4.3 \%$ ), and in a lesser extent for rice and maize (Figure 4b). Performance improvement systematically corresponded to albedo values lower than 0.2 , i.e. for crops with low amount of vegetation and wet or dark soil background. As compared to the simple linear multiple regression, the NNT were more flexible, thanks to both their non linear character and their larger degree of freedom (number of coefficients to be tuned, see last column of Table 4). This could explain the better performances observed in complex situations, with variable background properties and low amount of vegetation. Even if the obtained RMSE $E_{R}$ was $3.5 \%$, it could be set to $5 \%$, which corresponded to the accuracy of both albedometer measurements and FORMOSAT-2 corrected data. It is worth noting this NNT based empirical approach has never been applied to albedo estimation, and such results are quite encouraging. Further applications on other datasets would be necessary for additional validations.

\subsubsection{Dynamics of Albedo as estimated from FORMOSAT-2 data}

Figure 5 displays albedo dynamics captured throughout the study period from ground based measurements and NNT based FORMOSAT-2 retrievals, when considering all fields apart from meadow (Field \#3). It confirms the close agreement previously observed on Figure 4b, since we selected estimates from the best performing retrieval method. Dynamics of ground based albedo values measured at 10:30 UTC showed large variations, mainly due to daily changes in diffuse 
504 fraction of solar irradiance, and in a lesser extent to changes in surface properties. Conversely, 505 albedo estimates from FORMOSAT-2 depicted a reduced variability, because they corresponded to 506 data collection under clear sky conditions with a low diffuse component of solar irradiance.

Both wheat fields had comparable albedo dynamics, while bare soils exhibited contrasted time courses after harvesting (DOY 179), and especially after DOY 220 (pointed by an arrow in bottom left subplot of Figure 5). This was mainly due to green vegetation re-emergence in wheat Field \#1. Maize field dynamics showed limited amplitudes of variation, the few large changes being ascribed to irrigation practices. Dynamics of albedo for rice showed a significant increase when the canopy

513 developed. This was in agreement with observations from Maruyama et al. (2007) over rice crops.

514 Indeed, they reported a first period with low albedo values (around 0.10) that corresponded to low 515 vegetation cover overlaying a water or very wet soil background, and followed by an albedo increase during vegetation growth, until it stabilized around a value of 0.18 to 0.20 .

Figure 6 displays albedo dynamics captured throughout the study period from ground based measurements and NNT based FORMOSAT-2 retrievals, when considering Field \#3 (meadow) only. It is shown the good agreement between ground based observations and remotely sensed estimates. The amplitude of variation was limited, with almost neither seasonal trend nor large variations. This was mainly explained by irrigation or rainfall events, which induced a systematic albedo drop (between 0.01 and 0.04 ) that vanished after two or three days. Note that the cuts did not induce large albedo variation, probably because a significant fraction of green vegetation was kept. 


\subsection{LAl estimates from FORMOSAT-2 data}

531

532

533

534

535

536

537

538

539

540

541

542

543

544

545

546

547

548

549

550

551

552

553

554

\subsubsection{LAl as a function of individual reflectances}

Table 5 displays the parameters we obtained when calibrating the various empirical methods to be considered when retrieving LAI from FORMOSAT-2 data. Are also indicated the corresponding performances in terms of absolute bias, absolute and relative root mean square errors. We recall LAI references were obtained from ground based measurements through a temporal interpolation (§2.1.5). Statistical analysis through stepwise regression retained the Red and NIR wavebands only. As illustrated by Figure 7a that displays the "leave-one-out" cross-validation, the corresponding performances were significantly poor. Further, the $\mathrm{RMSE}_{\mathrm{R}}$ values displayed in Table 5 were larger than those obtained by Fassnacht et al. (1995), Eklundh et al. (2003) and Jensen and Binford (2004).

[Table 5]

[Figure 7]

As compared to the previous studies abovementioned, the lower performances we observed were explained by differences in land surface properties and remotely sensed information. Indeed, these former studies were devoted to the monitoring of forests from Landsat Thematic Mapper (TM), thus benefiting from both lower spatial heterogeneities, and from additional spectral information through shortwave infrared (SWIR) wavebands. For the current study, the significantly poor performances were ascribed to several factors. The first one was the large variabilities of canopy structure and soil background properties, to be both taken into account with three freedom degrees only (Table5). Second, the absence of FORMOSAT-2 SWIR waveband may contribute to the poorer performances in LAI estimation. Indeed, Eklundh et al. (2003) obtained a significant contribution of the SWIR 
wavebands while estimating the LAI over a forest using the multiple regression approach.

556

557 Rice was the unique field for which albedo was reasonably well estimated, all the other fields

558 corresponding to large scattering between measured and estimated values. Although stepwise

559 multiple linear regression could have been independently applied over each of the four land cover

560 classes, the restricted data set would have prevented from obtaining robust relationships.

561 Additionally, the maize field was quite heterogeneous, and the ground sampling was probably too

562 small to obtain a representative value of the field LAI.

563

564 Training of neural networks over individual reflectances $\left(\mathrm{NNT}_{\mathrm{Ref}}\right)$ showed significant

565 improvements of retrieval performances. The RMSE values were indeed twice lower (Table 5 first

566 line as compared to second one, and Figure 7c as compared to Figure 7a). This was ascribed to the

567 larger number of coefficients to be tuned (Table 5). Regardless of the considered field, the 568 scattering between estimated and measured LAI values (Figure 7c) was similar.

\subsubsection{LAl as a function of NDVI}

572 Table 5 and Figure $7 \mathrm{~b}$ show that both the NDVI based heuristic formulation (exponential shape) 573 approach and the NDVI based neural network approach $\mathrm{NNT}_{\mathrm{NDVI}}$ performed better than the 574 reflectances based approaches, whether it was NTB conversion or NNT.

575

576 A unique set of parameters for the heuristic formulation (Equation 4) was adjusted over the whole

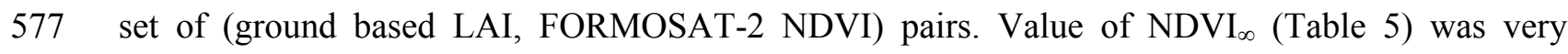
578 comparable to those obtained by Weiss et al. (2002b) and Wilson and Meyers (2007) over similar 579 vegetation types but with different viewing angles (nadir looking with these former studies, against 
$41^{\circ}$ zenith $/ 239^{\circ}$ azimuth with the current study), and probably different solar directions. This may

581 explain why $\mathrm{K}_{\mathrm{LAI}}$ value obtained in the current study (0.71) was slightly larger than that obtained

582 (0.67) by Weiss et al. (2002b). The NDVI normalization properties appeared to be efficient. With

583 three freedom degrees only, better performances were obtained than with the 11 freedom degree of

584 the reflectance based NNT method, the $\mathrm{RMSE}_{\mathrm{R}}$ dropping down by $20 \%$ in relative.

Training a neural network with measured LAI and NDVI values allows more flexibility in the shape of the relationship between these two variables. Seven parameters had indeed to be tuned, as compared to three parameters when using heuristic formulation (Equation 4). Results show this method performed best, with a RMSE $E_{R}$ value of 27.54\% (Table 5 and Figure 7d). These good performances were ascribed to the combined effect of NDVI efficient normalization properties and the NNT flexibility. However, saturation problems still were observed for LAI values larger than 4, a problem that may result from the saturation of the remotely sensed signal over the optical domain.

Figure 8 illustrates the LAI - NDVI relationship generated by both the $\mathrm{NNT}_{\mathrm{NDVI}}$ and the heuristic Equation 4. The figure also shows how the heterogeneous, row-planted maize crop exhibited a different behavior than the other homogeneous vegetation covers. This heterogeneity in structure and field cover could have made the LAI - NDVI relationship quite different over this crop. Consequently, the latter was not well characterized through the multi-crop calibrated relationship.

\subsubsection{Dynamics of LAl as estimated from FORMOSAT-2 data}


606

607

608

609

610

611

612

613

614

615

616

617

618

619

620

621

622

623

624

625

626

627

628

630

smooth, as expected (Figure 9). Dynamics showed a classical temporal pattern for wheat, maize and rice, with increase LAI during the vegetative growth, followed by a relatively rapid senescence. Rice and maize crops depicted bare soil conditions $(\mathrm{LAI}=0)$ at the beginning. Wheat fields showed significant amount of green vegetation after harvest $(\mathrm{LAI} \approx 0.4)$, presumably corresponding to weeds that developed after the rainfall events observed around DOY 255. Dynamics of meadow shows the three cuts and the re-emergence just afterwards. Note that since LAI was around one just after the cuts, this explains why the albedo dynamics was not affected by these cuts.

\subsection{LAl versus Albedo}

[Figure 9]

NNT based FORMOSAT-2 retrievals of both LAI and albedo over the whole study area were matched for all vegetation types and for all acquisition dates. Figure 10 displays the resulting boxplots along with the corresponding statistics (mean value, lower and upper quartiles), and the ground based measurements. It is shown when LAI increases, albedo follows almost the same trend for wheat, meadow and maize. However, rice behaves differently, and especially for LAI values lower than 2.5. The general trend observed over the whole area from FORMOSAT-2 retrievals was similar to that observed over the five fields where measurements were collected. However, most of the field data were outside the $95 \%$ confidence interval of albedo variation within each LAI class. This indicated although ground based data were representative of each field as shown by the low $\mathrm{CV}$ values in Table 1, the fields were not representative of the land use classes. Although this was not expected, consequences on the empirical models calibrated for estimating LAI and albedo might be marginal. Indeed, calibrations were performed by including all crops and dates, while LAI and albedo measured values covered most of the ranges observed across the study area and period. 
634 Figure 11 displays the LAI - albedo relationship simulated from radiative transfer modeling (§ 3.5).

635 For the investigated crops, these simulations agree very well with observations displayed on 636 Figure 10. The soil background played a major role for low to moderate LAI values $(\mathrm{LAI}<3)$, which 637 could explain the differences observed between the four different crop types. For larger LAI values, 638 albedo tends towards an asymptotic value that may depend on canopy architecture (leaf inclination) 639 as well as on other variables not investigated here like chlorophyll content and mesophyll structure 640 parameter. The largest albedo variability within a LAI class, depicted in Figure 10, corresponded to 641 intermediate LAI values $(1<\mathrm{LAI}<2.5)$, where both soil background and vegetation influence the 642 reflected radiation. The albedo ranges were slightly lower for LAI lower than 1, because the main 643 influence was due to different soil surface reflectance properties. For LAI larger than 2.5, the albedo 644 range kept on decreasing with increasing LAI where the vegetation reflectance properties dominate.

645

646 647
[Figure 11]

\section{Conclusion}

This study demonstrated that it is possible accurately retrieving albedo and LAI from the specific FORMOSAT-2 observations, along with empirical approaches based on restricted spatial sampling but continuous monitoring. Although calibrations were performed by including all data collection dates and all crops (wheat, maize, rice and meadow), very good performances were achieved. Further, the advantages of the neural network techniques (NNT) over linear multiple regressions or heuristic formulations was demonstrated. For the first time an NNT based method was used to 
656

657

658

659

660

661

662

663

664

665

666

667

668

669

670

671

672

673

674

675

676

677

678

679

680

681

retrieve albedo, and the results were quite encouraging.

Due to the relatively small sample size, the empirical models established for retrieving LAI and albedo probably need additional independent evaluation about their robustness, with emphasis on the sampling strategy that optimizes the number, locations and dates of the ground based measurements. When applied over orchards and vineyards, attention should also be paid to row orientations relatively to solar or viewing directions. Furthermore, these relationships were calibrated under the specific FORMOSAT-2 viewing conditions that are latitude / longitude dependent (here, zenith angle $=41^{\circ}$ and azimuth angle $=239^{\circ}$ ). Application to other conditions may require adaptations, either by using radiative transfer models if well calibrated over the considered surfaces, or by replicating the whole experimental process under these new conditions.

Alternative approaches based on radiative transfer model inversion were not considered in this study, and should require further efforts. This might be possible under conditions of well defined prior information, given single multi-date and multi-crop calibration of empirical approaches yielded accurate estimates of LAI and albedo, and this in spite of limited information provided by the FORMOSAT-2 samplings (three wave bands and a single off nadir viewing direction).

Another original output of this study was the possibility to investigate the spatial correlation between albedo and LAI. We observed great consistencies when comparing albedo - LAI relationships derived from ground based data, remotely sensed observations, or radiative transfer simulations; with specific trends according to vegetation types. However, we observed large albedo variabilities within most LAI classes, particularly for low leaf area indices. It appeared therefore that estimating one variable from the other would yield poor performances, particularly for low LAI values under varying soil background conditions. Conversely, albedo may be estimated to be around 0.2 for LAI values larger than 4 , at least for the canopy we considered. 
683 This study also highlighted the interest of frequent observations at high spatial resolution for 684 vegetation monitoring. It allowed obtaining detailed features of the dynamics from which several 685 information could be derived; in relation with either brutal changes resulting from cultural practices 686 (cuts, irrigation under certain conditions) or more smooth evolutions resulting from canopy 687 phenology and functioning. In the context of exhaustively describing the spatiotemporal variability 688 of surface properties, this study finally demonstrated the potentials of the synergy between 6891 / ground based web-sensors that continuously monitor specific biophysical variables over few 690 locations, and 2/ high revisit frequency and high spatial resolution satellite images.

691

\section{Acknowledgments}

693

694 This study was part of projects financed by the MIP-PACA regions in France and by the CNES 695 (DAR 2006 TOSCA). This work was done thanks to the post-doctoral financial support of INRA 696 'Environnement et Agronomie' department. The FORMOSAT-2 images used in this paper are $697{ }^{\circ}$ NSPO (2006) and distributed by SPOT Image S.A. all rights reserved. We would like to thank 698 farmers for allowing us to make use of their fields for various measurements, Jean-François Hanocq 699 for his technical contribution, Françoise Ruget for her agronomy expertise and Jean-Claude Mouret 700 of INRA Montpellier for providing us with information on rice plantations. 701 702 703 


\section{REFERENCES}

705

706

707

708

709

710

711

712

713

714

715

716

717

718

719

720

721

722

723

724

725

726

727

728

729

Asrar, G., Fuchs, M., Kanemasu, E.T., \& Hatfield, J.L. (1984). Estimating absorbed photosynthetic radiation and leaf area index from spectral reflectance in wheat. Agronomy J, 76, 300-306.

Bacour, C., Jacquemoud, S., Leroy, M., Hautecoeur, O., Weiss, M., Prevot, L., Bruguier, N., \& Chauki, H. (2002). Reliability of the estimation of vegetation characteristics by inversion of three canopy reflectance models on airborne POLDER data. Agronomie, 22, 555-565.

Baillarin, S., Gleyzes, J.P., Latry, C., Bouillon, A., Breton, E., Cunin, L., Vesco, C., \& Delvit, J.M. (2004). Validation of an automatic image orthorectification processing. IGARSS's Proceedings, 20-24 Sept. 2004, 2, 1398- 1401, ISBN: 1390-7803-8742-1392.

Baret, F., \& Buis, S. 2008. Estimating canopy characteristics from remote sensing observations. Review of methods and associated problems. In S. Liang (Ed.), Advances in Land Remote Sensing: System, Modelling, Inversion and Application. Springer.

Baret, F., \& Guyot, G. (1991). Potentials and limits of vegetation indices for LAI and PAR assessment. Remote Sensing of Environment, 35, 161-173.

Baret, F., J. G. P. W. Clevers, \& Steven, M.D. (1995). The robustness of canopy gap fraction estimates from red and near infrared reflectances: a comparison of approaches. Remote Sensing of Environment, 54, 141-151.

Baret, F., Schaaf, C., Morisette, J., \& Privette, J. (2005). Report on the Second International Workshop on Albedo Product Validation. Earth Observer, 17, 13-17.

Brest, C. L., \& Goward, S. N. (1987). Deriving surface albedo measurements from narrow band satellite data. International Journal of Remote Sensing, 8, 351-367.

Chen, J.M., \& Black, T.A. (1992). Defining leaf area index for non-flat leaves. Plant and Cell Environment, 15, 421-429.

Chern, J.S., Wua, M. and Lin, S. (2006). Lesson learned from FORMOSAT-2 mission operations. Acta Astronautica, 59, 344-350. 
Combal, B., F., Baret, M., Weiss, A., Trubuil, D., Macé, A., Pragnère, R., Myneni, Y., Knyazikhin, \& Wang., L. (2002). Retrieval of canopy biophysical variables from bidirectional reflectance data. Using prior information to solve the ill-posed inverse problem. Remote Sensing of Environment, 84, 1-15.

Courault, D., Bsaibes, A., Kpemlie, E., Hadria, R., Hagolle, O., Marloie, O., Hanocq, J.F., Olioso, A., Bertrand, N. and Desfonds, V. (2008). Assessing the Potentialities of FORMOSAT-2 Data for Water and Crop Monitoring at Small Regional Scale in South-Eastern France. Sensors, 8, $3460-3481$.

Darvishzadeh, R., Skidmore, A., Schlerf, M. and Atzberger, C. (2008). Inversion of a radiative transfer model for estimating vegetation LAI and chlorophyll in a heterogeneous grassland. Remote Sensing of Environment. Earth Observations for Terrestrial Biodiversity and Ecosystems Special Issue, 112, 2592-2604.

Dedieu, G., Karnieli, A., Hagolle, O., Jeanjean, H., Cabot, F. Ferrier, P. \& Yaniv, Y. (2006). VENuS: A joint French - Israel Earth Observation scientific mission with High spatial and temporal resolution capabilities. In: J. Sobrino (Editor), Second Recent Advances in Quantitative Remote Sensing. Publicacions de la Universitat de València, 25-29 September 2006, Auditori de Torrent, Spain, pp. 517-521.

Demarez, V., Duthoit, S., Baret, F., Weiss, M., \& Dedieu, G. (2008). Estimation of leaf area and clumping indexes of crops with hemispherical photographs. Agricultural and Forest Meteorology, 148, 644-655.

Durbha, S., R. Kinga, and N. Younan. (2007). Support vector machines regression for retrieval of leaf area index from multiangle imaging spectroradiometer. Remote Sensing of Environment, $107,348-361$.

Eklundh, L., Hall, K., Eriksson, H., Ardö, J., \& Pilesjö, P. (2003). Investigating the use of Landsat thematic mapper data for estimation of forest leaf area index in southern Sweden. Canadian Journal of Remote Sensing, 29, 349-362. 
Fassnacht, K.S., Gower, S.T., MacKenzie, M.D., Nordheim, E.V., \& Lillesand, T.M. (1997). Estimating the leaf area index of North Central Wisconsin forests using the Landsat thematic mapper. Remote Sensing of Environment, 61, 229-245.

Garrigues, S., Allard, D. \& Baret., F. (2007). Using first- and second-order variograms for characterizing landscape spatial structures from remote sensing imagery. IEEE Transactions on Geoscience and Remote Sensing. 45, 1823-1834.

Geisser, S. (1975). The predictive sample reuse method with applications. Journal of the American Statistical Association, 70, 320-328.

Greuell, W., \& Oerlemans, J. (2004). Narrowband-to-broadband albedo conversion for glacier ice and snow: equations based on modeling and ranges of validity of the equations, Remote Sensing of Environment, 89(1), 95-105.

GCOS (2006). Satellite-based products for climate. Supplemental details to the satellite- based component of the "Implementation Plan for the Global Observing System for Climate in Support of the UNFCCC", GCOS-107 (WMO/TD No. 1338). 90p.

Goel, N.S. (1989). Inversion of canopy reflectance models for estimation of biophysical parameters from reflectance data. In: G. Asrar (Editor), Theory and Applications of Optical Remote Sensing, Wiley \& Sons, New York, 205-251.

Hagan, M.T., and Menhaj, M. (1994). Training feed-forward networks with the Marquardt algorithm, IEEE Transactions on Neural Networks, 5, 989-993.

Hagolle, O., Dedieu, G., Mougenot, B., Debaeker, V., Duchemin, B., \& Meygret, A. (2008). Correction of aerosol effects on multitemporal images acquired with constant viewing angles: Application to Formosat-2 images. Remote Sensing of Environment, 112, 1689-1701.

Jacob, F., Weiss, M., Olioso, A., \& French, A. (2002a). Assessing the narrowband to broadband conversion to estimate visible, near infrared and shortwave apparent albedo from airborne PolDER data. Agronomie, 22, 537-546. 
Jacob, F., Olioso, A., Weiss, M., Baret, F., \& Hautecoeur, O. (2002b). Mapping short-wave albedo of agricultural surfaces using airborne PolDER data. Remote Sensing of Environment, 80, 3646.

Jacob, F. \& Olioso, A. (2005). Derivation of diurnal courses of albedo and reflected solar irradiance from airborne POLDER data acquired near solar noon. Journal of Geophysical Research, 110, D10104.

Jacobs, A.F.G. and van Pul, W.A.J. (1990). Season changes in the albedo of maize crop during two seasons. Agricultural and Forest Meteorology, 49, 351-360.

Jacquemoud S., Verhoef W., Baret F., Bacour C., Zarco-Tejada P.J., Asner G.P., François C. \& Ustin S.L. (2008). PROSPECT + SAIL Models: a review of use for vegetation characterization, Remote Sensing of Environment, in press.

Jiang Z., Huete, A., Didan, K., Miura, T. (2008). Development of a 2-band Enhanced Vegetation Index without a blue band. Remote Sensing of Environment, 112(10), 3833-3845.

Koetz, B., Baret, F., Poilve, H., \& Hill, J. (2005). Use of coupled canopy structure dynamic and radiative transfer models to estimate biophysical canopy characteristics. Remote Sensing of Environment, 95, 115-124.

Liang, S., Strahler, A.H., \& Walthall, C.W. (1999). Retrieval of land surface albedo from satellite observations: a simulation study. Journal of applied Meteorology, 38, 712-725.

Liang, S. (2001). Narrowband to broadband conversions of land surface albedo I: Algorithms. Remote Sensing of Environment, 76, 213-238.

Liang, S., Shuey, C.J., Russ, A.L., Fang, H., Chen, M., Walthall, C.L., Daughtry, C.S.T., \& Hunt, E.R.J. (2002). Narrowband to broadband conversions of land surface albedo: II Validation. Remote Sensing of Environment, 84, 25-41.

Liang, S. (2003). A direct algorithm for estimating land surface broadband albedos from MODIS imagery. IEEE Transactions on Geoscience and Remote Sensing, 41(1), 136-145. 
806

807

808

809

810

811

812

813

814

815

816

817

818

819

820

821

822

823

824

825

826

827

828

829

830

831

Liang, S., Yu, Y., \& Defelice, T.P. (2005). VIIRS narrowband to broadband land surface albedo conversion: formula and validation. International Journal of Remote Sensing, 26(5), 10191025.

Lucht, W. (1998). Expected retrieval accuracies of bidirectional reflectance and albedo from EOSMODIS and MISR angular sampling. Journal of Geophysical Research, 103, 8763-8778.

Lucht, W. \& Roujean, J.L. (2000). Considerations in the parametric modeling of BRDF and albedo from multi-angular satellite sensor observations. Remote Sensing Reviews, 18, 343-379.

Martimort, P. (2007). Sentinel-2 - the optical high-resolution mission for GMES operational services. ESA Bulletin, 131, 18 - 23.

Maruyama, A., Kuwagata, T., Ohaba, K., \& Maki, T. (2007). Dependence of solar radiation transport in rice canopies on developmental stage. Japanese Agricultural Research Quarterly, $41,39-45$.

Meroni, M., Colombo, R. and Panigada, C. (2004). Inversion of a radiative transfer model with hyperspectral observations for LAI mapping in poplar plantations. Remote Sensing of Environment, 92, 195-206.

Nilson, T. (1971). A theoretical analysis of the frequency of gaps in plant stands. Agricultural Meteorology, 8, 25-38.

Olioso, A. (1992). Simulation des échanges d'énergie et de masse d'un couvert végétal, dans le but de relier la transpiration et la photosynthèse aux mesures de reflectance et de température de surface. PhD Thesis, Université de Montpellier 2.

Pokrovsky, O., and Roujean, J.L. (2003). Land surface albedo retrieval via kernel-based BRDF modeling: I. Statistical inversion method and model comparison. Remote Sensing of Environment, 84, 100-119.

Russell, M.J., Nunez, M., Chladil, M.A., Valiente, J.A., \& Lopez-Baeza, E. (1997). Conversion of Nadir, narrow-band reflectance in red and near-infrared channels to hemispherical surface albedo. Remote Sensing of Environment, 61, pp. 16-23. 
832

833

834

835

836

837

838

839

840

841

842

843

844

845

846

847

848

849

850

851

852

853

854

855

Schaaf, C.B., Gao, F., Strahler, A.H., Lucht, W., Li, X.W., Tsang, T., Strugnell, N.C. Zhang, X.Y. Jin, Y.F., Muller, J.P., Lewis, P., Barnsley, M., Hobson, P., Disney, M., Roberts, G., Dunderdale, M., Doll, C., d'Entremont, R.P., Hu, B.X., Liang, S, Privette, L.J.L., and Roy. D. (2002). Firt operational BRDF, albedo nadir reflectance products from MODIS. Remote Sensing of Environment, 83, 135-148.

Scherer, S., \& Kriscke, M. (2001). The RapidEye optical satellite family for high resolution imagery. Programmetric Week, 1, 139-145.

Schlerf, M., \& Atzberger, C. (2006). Inversion of a forest reflectance model to estimate structural canopy variables from hyperspectral remote sensing data. Remote Sensing of Environment, $100,281-294$.

Song, J., \& Gao, W. (1999). An improved method to derive surface albedo from narrowband AVHRR satellite data: Narrowband to broadband conversion. Journal of Applied Meteorology, 38, 239-249.

Stone, M. (1974). Cross-validatory choice and assessment of statistical predictions. Journal of the Royal Statistical Society (Series B), 36, 111-147.

Susaki, J., Yasuoka, Y., Kajiwara, K., Honda, Y., \& Hara, K. (2007). Validation of MODIS Albedo Products of Paddy Fields in Japan. IEEE Transactions on Geoscience and Remote Sensing, $45,206-217$

van Leeuwen, W.J.D., \& Roujean, J.-L. (2002). Land surface albedo from the synergistic use of polar (EPS) and geo-stationary (MSG) observing systems: An assessment of physical uncertainties, Remote Sensing of Environment, 81 (2-3), 273-289.

Vermote, E. F., Tanré D., Deuzé J. L., Herman M. \& Mocrette J. J. (1997). Second simulation of the satellite signal in the solar spectrum, 6S: an overview. IEEE Transactions on Geoscience and Remote Sensing, 35, 675-686. 
856

857

858

859

860

861

862

863

864

865

866

868

869

870

871

872

873

874

875

876

877

878

879

880

Walthall, C., Dulaney, W., Anderson, M., Norman, J., Fang, H. and Liang, S. (2004). A comparison of empirical and neural network approaches for estimating corn and soybean leaf area index from Landsat ETM+ imagery. Remote Sensing of Environment, 92, 465-474.

Wanner, W., Strahler, A., Hu, B., Lewis, P., Muller, J.-P., Li, X., Barker-Schaaf, C., \& Barnsley, M. (1997). Global retrieval of bidirectional reflectance and albedo over land from EOS MODIS and MISR data: theory and algorithm. Journal of Geophysical Research, 102, 1714317161.

Weiss, M., Baret, F., Leroy, M., Begué, A., Hautecoeur, O., \& Santer, R. (1999). Hemispherical reflectance and albedo estimates from the accumulation of across track sun synchroneous satellite data. Journal of Geophysical Research, 104, 221-232.

Weiss, M., Baret, F., Myneni, R.B., Pragnère, A., \& Knyazikhin, Y. (2000). Investigation of a model inversion technique to estimate canopy biophysical variables from spectral and directional reflectance data. Agronomie, 20, 3-22.

Weiss, M., Jacob, F., Baret, F., Pragnère, A., Bruchou, C., Leroy, M., Hautecoeur, O., Prevot L. and Bruguier, N. (2002a). Evaluation of kernel-driven BRDF models for the normalization of Alpilles/ReSeDA POLDER data. Agronomie, 22, 531-536.

Weiss, M., Baret, F., Leroy, M., Hautecoeur, O., Bacour, C., Prévot, L., \& Bruguier, N. (2002b). Validation of neutral techniques to estimate canopy biophysical variables from remote sensing data. Agronomie, 22, 133-158.

Weiss, M., Baret, F., Smith, G.J., \& Jonckheere, I. (2004). Methods for in situ leaf area index measurement, part II: from gap fraction to leaf area index: retrieval methods and sampling strategies. Agricultural and Forest Meteorology, 121, 17-53.

Wilson, T., \& Meyers, T. (2007). Determining vegetation indices from solar and photosynthetically active radiation fluxes. Agricultural and Forest Meteorology, 144, 160-179. 
881 LIST OF FIGURES

882 


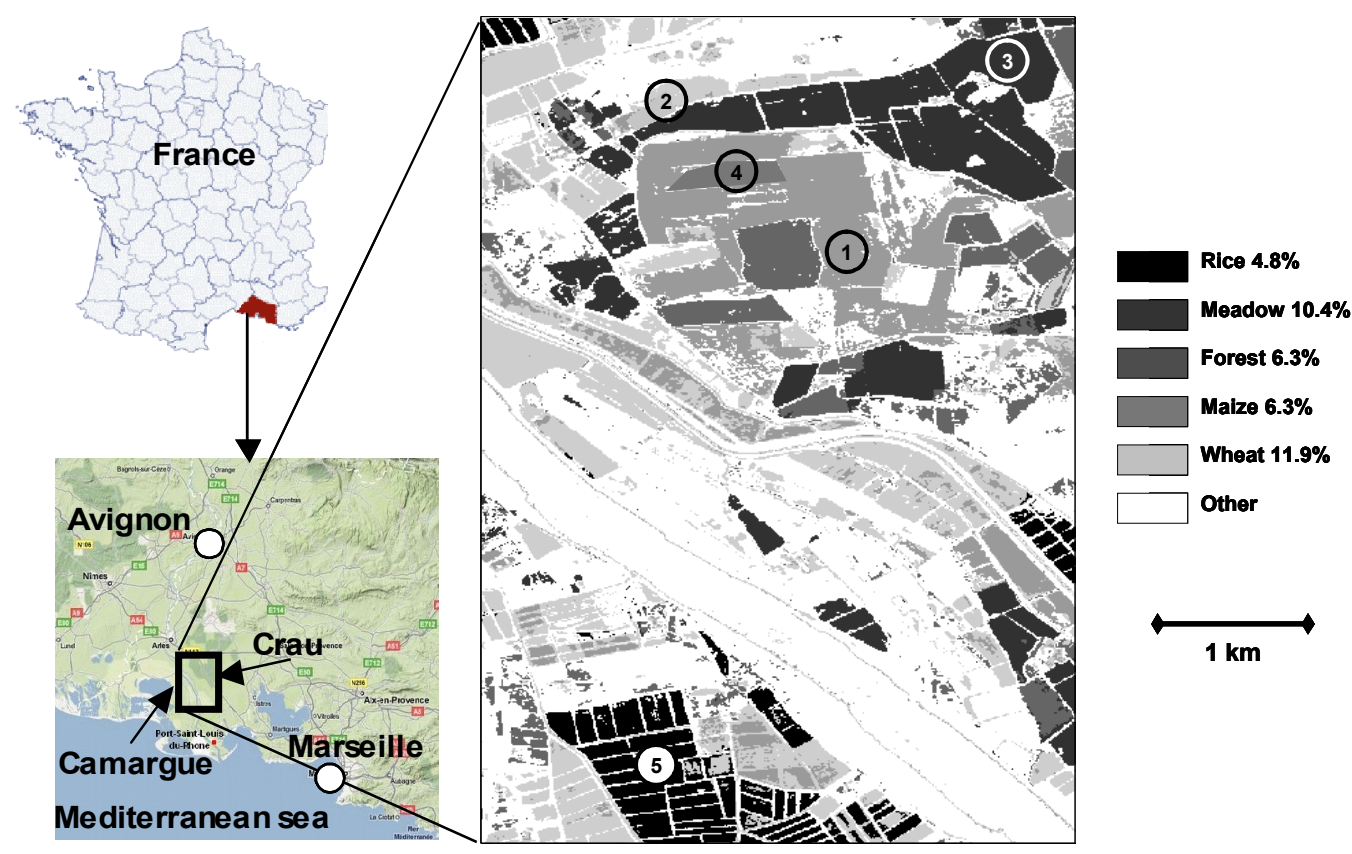

886 Figure 1: Land use map of the "Crau-Camargue" study area. The major cultivations are represented with their 887 occupation occurrence over the experimental area. Ground measurements took place from March to October 8882006 over fields that were numbered \#1 and \#2 for wheat (turning to bare soils at the end of June), \#3 for 889 meadow, \#4 for maize and $\# 5$ for rice.

890 


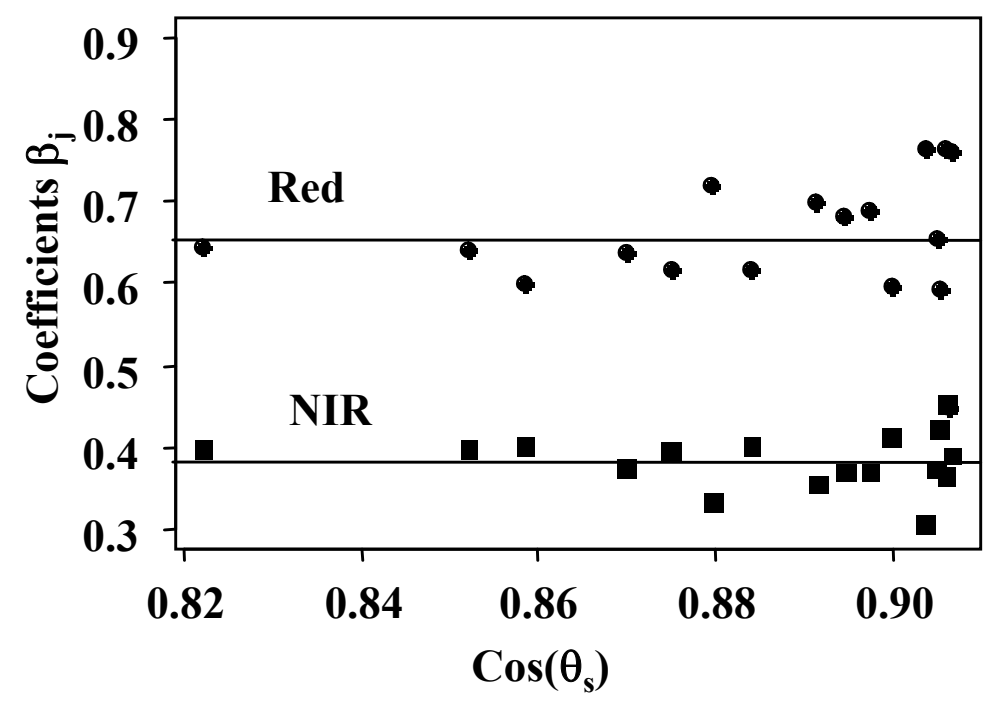

894

895 Figure 2: Narrowband-To-Broadband (NTB) conversion coefficients $\beta_{\mathrm{j}}$ in the Red and NIR bands, computed for 896 albedo retrieval, for each individual observation date as a function of the solar zenith angle $(\theta$ s) cosine. 


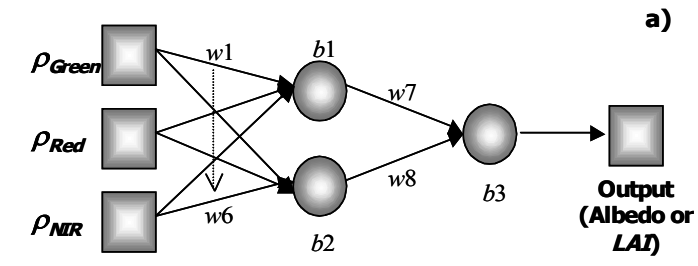

a)

b)

901

902 Figure 3: Neural network architecture when inputs were a) the green, red, and near infrared reflectances ( $\rho)$ and

903 b) NDVI only. The squares represent the input and output variables, and the circles represent both the two

904 tangent sigmoid neurons of the hidden layer and the single linear neuron of the output layer. The network

905 structure required for a) 11 coefficients to be tuned: eight weights (w1...w8) and three biases (b1...b3) and for

906 b) seven coefficients to be tuned: four weights (w1...4) and three biases (b1...b3).

907

908 

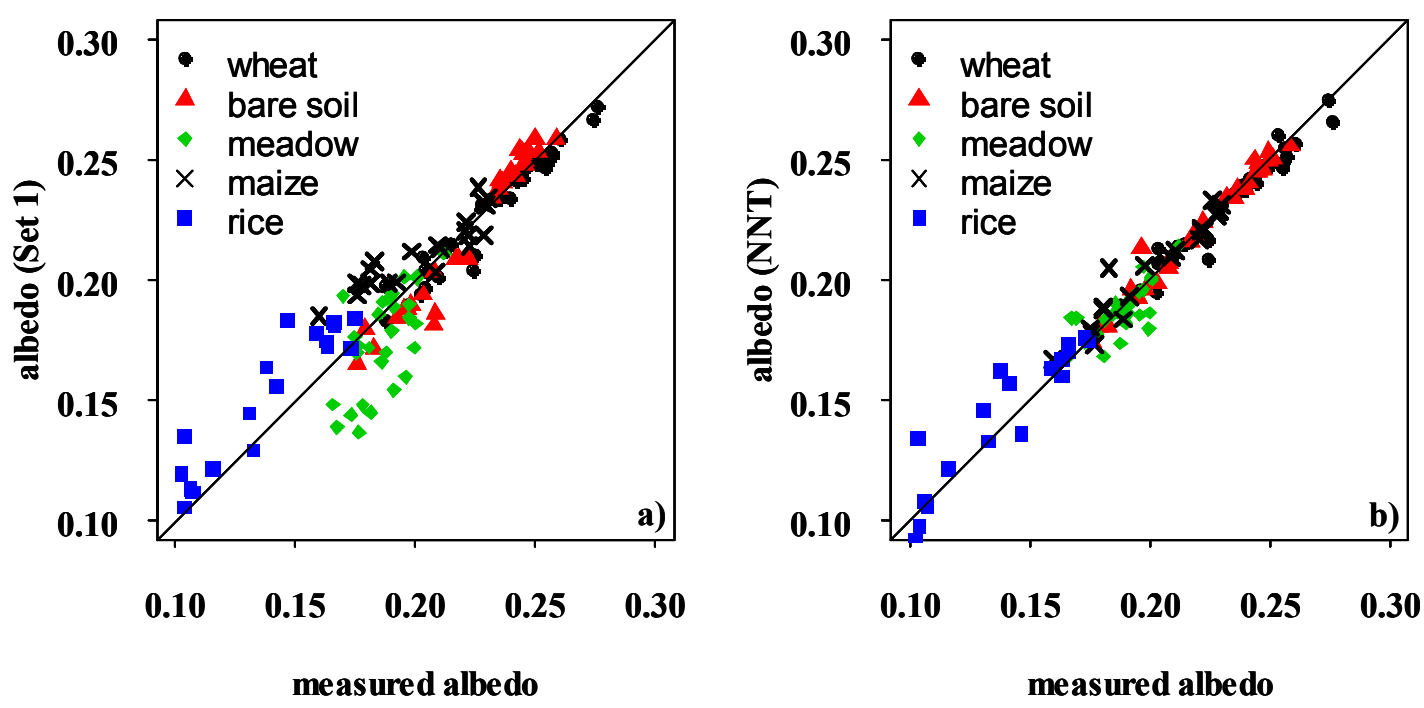

910

911

912 Figure 4: Comparison, over the four considered crops, between ground based measured albedo and

913 FORMOSAT-2 retrievals based on (a) the coefficient Set 1 and (b) the NNT. Scatterplots correspond to the 914 leave-one-out validation data set. The 5 fields are identified by different symbols.

915

916 

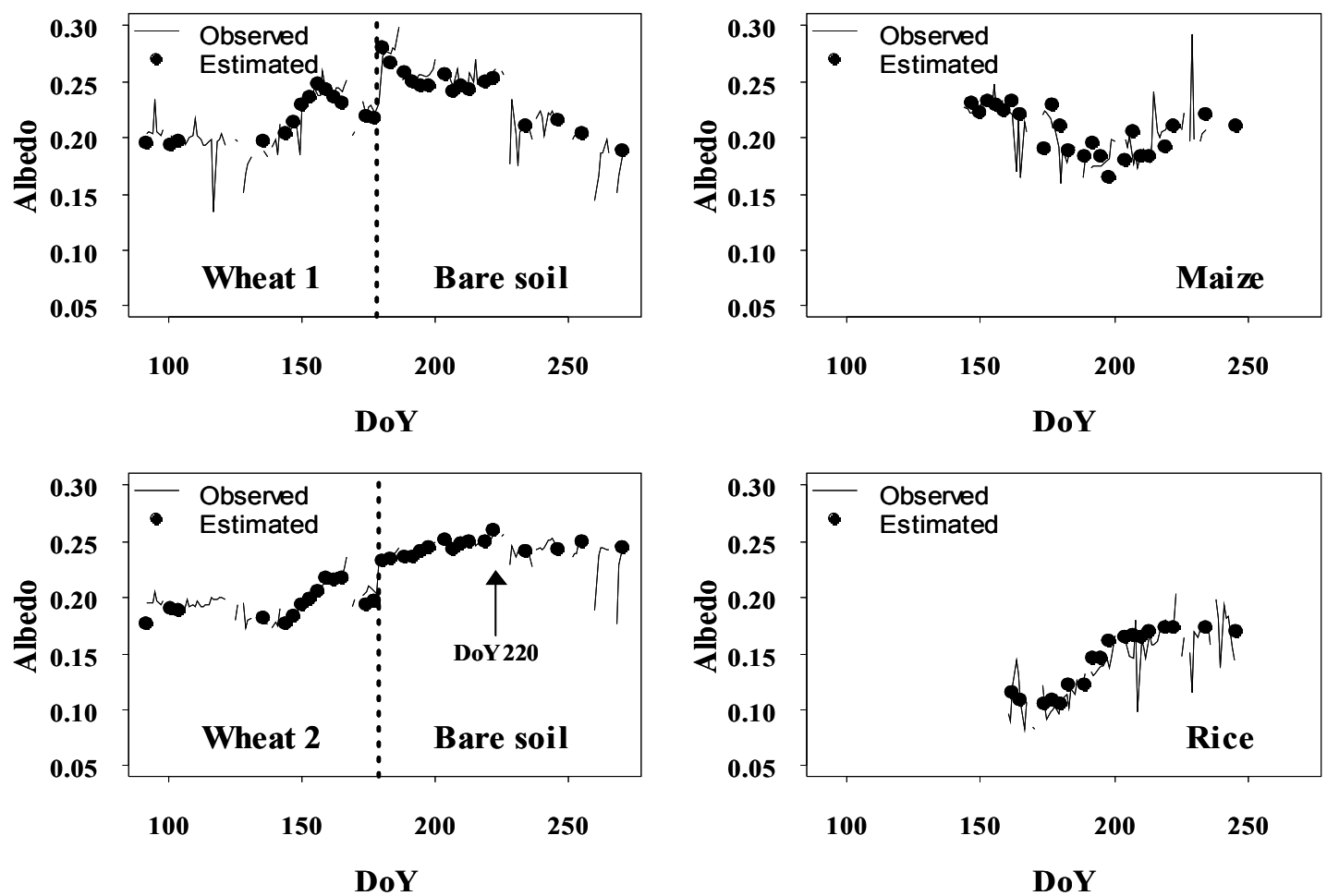

919

920 Figure 5: Albedo dynamics captured throughout the study period from ground based measurements (labeled

921 observed) and FORMOSAT-2 retrievals using the neural network method (labeled estimated), when considering wheat / bare soil (Field \#1 and 2), maize (Field \#4) and rice (Field \#5). Dotted vertical lines indicate the harvest dates. DOY 220 discussed in the text is pointed by an arrow on the Wheat 2 figure (bottom left subplot). 


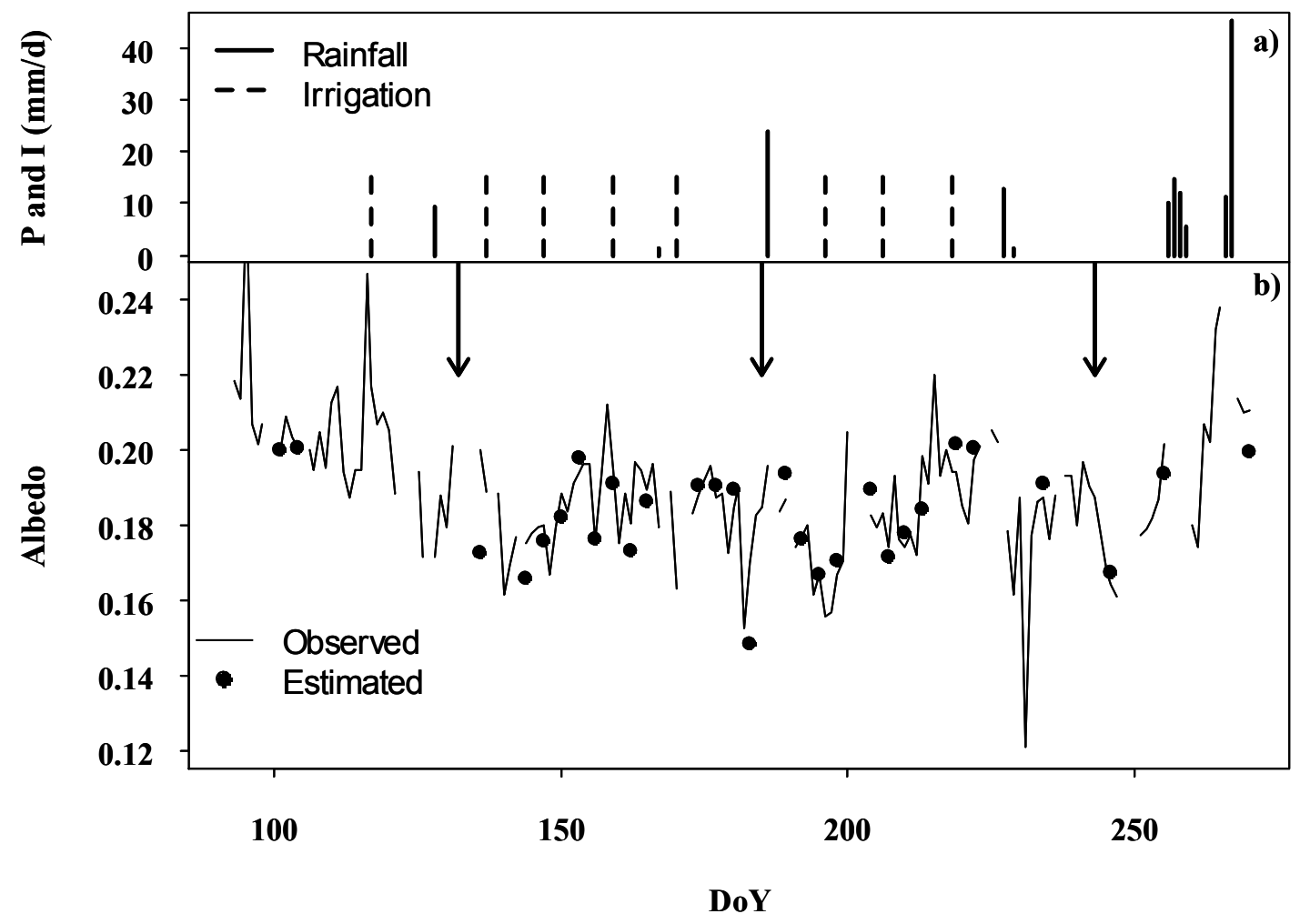

929 Figure 6: Albedo dynamics captured throughout the study period from ground based measurements (labeled 930 observed) and FORMOSAT-2 retrievals using the neural network method (labeled estimated), when considering 931 irrigated meadow (Field \#3). For analysis, albedo dynamics (bottom) is plotted with rainfall and irrigation events 932 (top). Meadow cuts are illustrated by vertical arrows.

933

934 

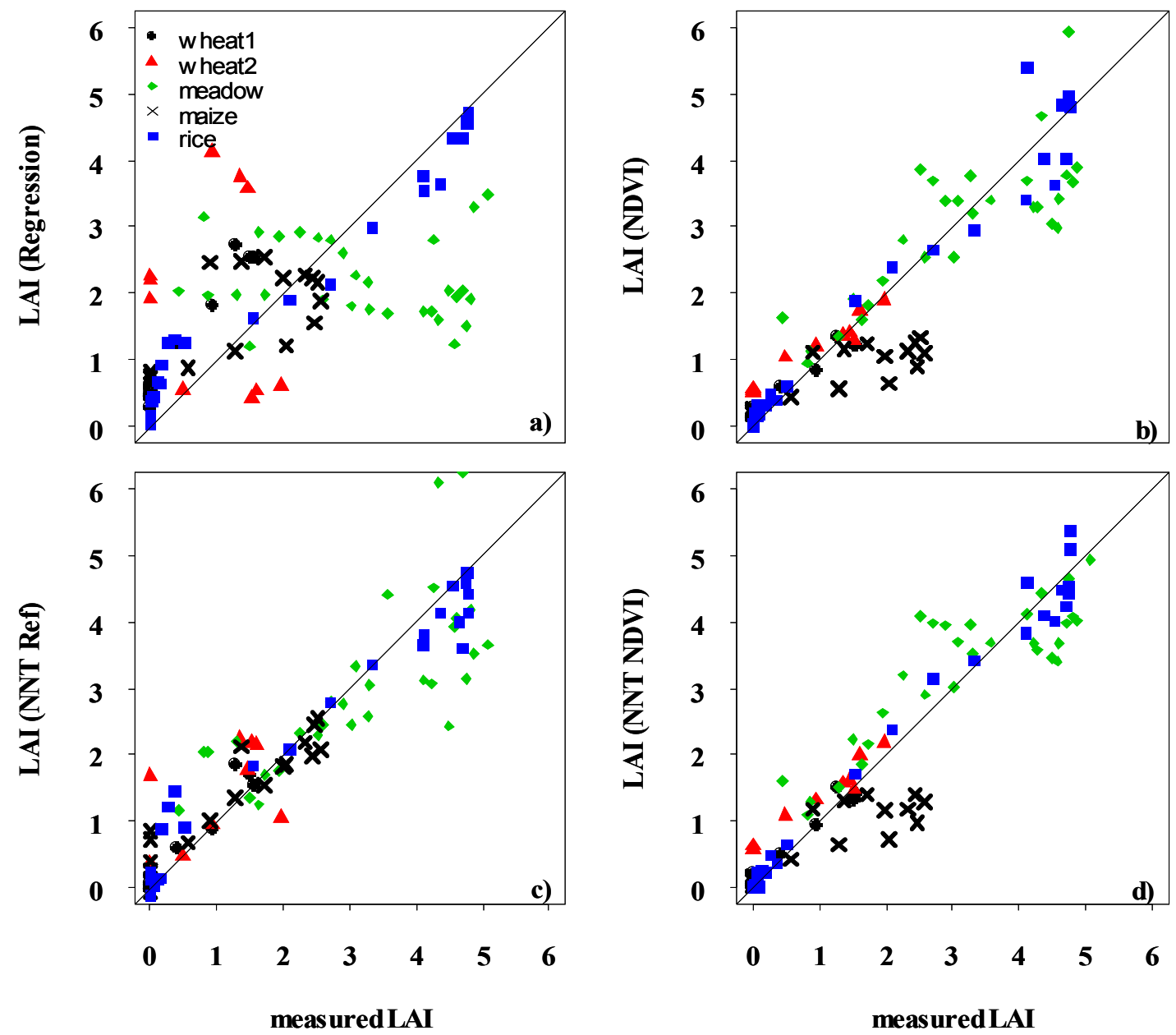

936

938 Figure 7: Leave-one-out cross-validation, over the four considered crops, of FORMOSAT-2 LAI retrievals 939 against ground based measurements, where the latter were temporally interpolated through Equation 1.

940 Estimates are derived from a) multiple regression, b) neural network technique (NNT) based method with 941 reflectances as inputs, c) NDVI based heuristic formulation (Equation 4), and d) NNT based method with NDVI 942 as input. 


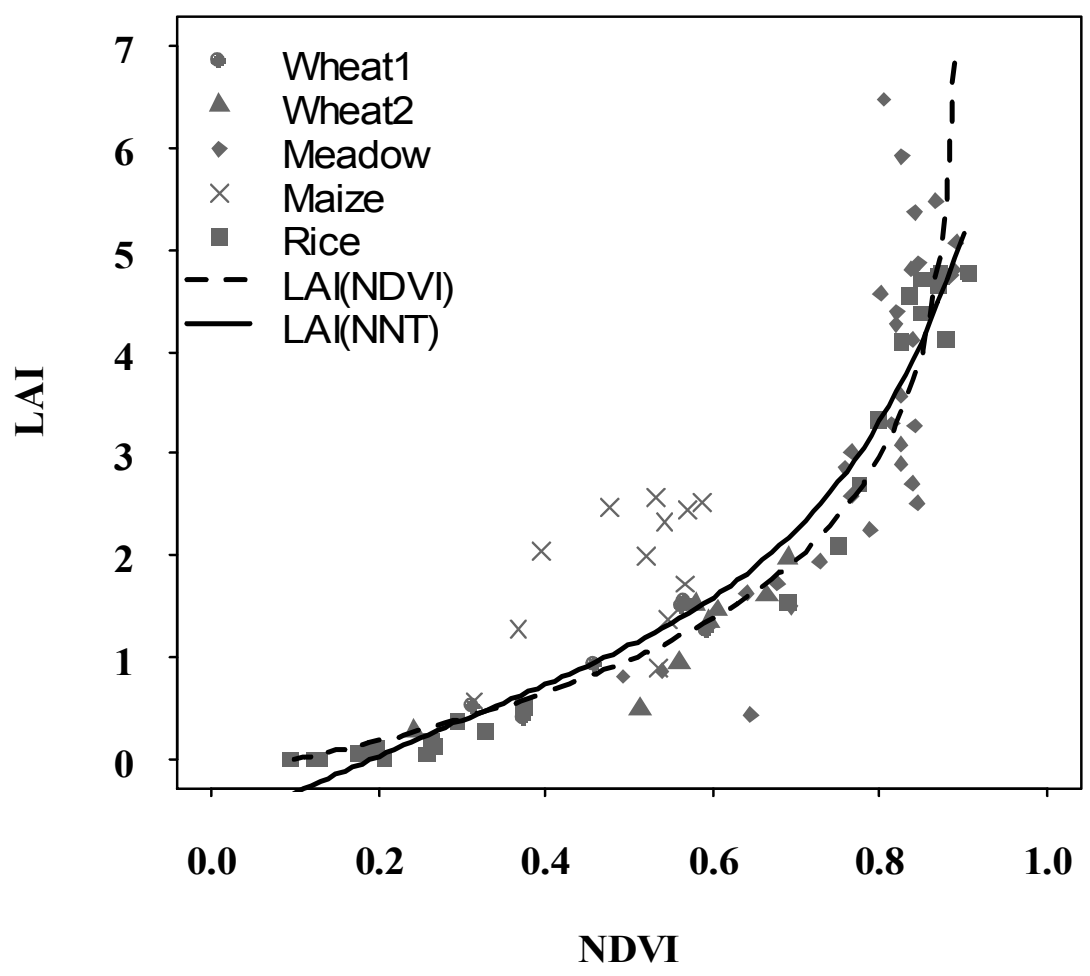

948 Figure 8: Comparison between the LAI versus NDVI relationships, as obtained by the NDVI exponential law 949 method $\left(\mathbf{L A I}_{\mathrm{NDVI}}\right)$ or by the neural network method $\left(\mathrm{LAI}_{\mathrm{NNT}}\right)$.

950

951 


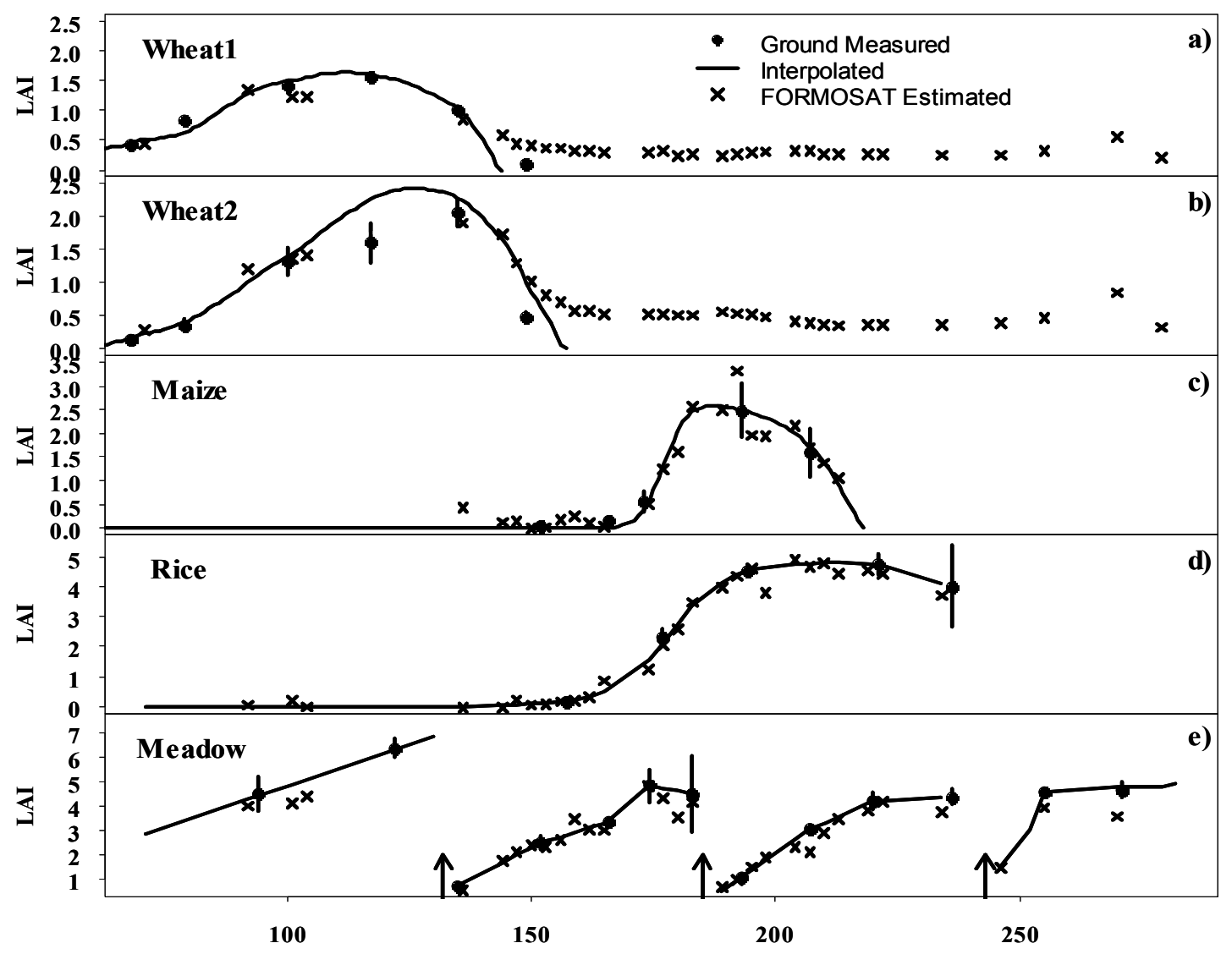

955 Figure 9: Dynamics of LAI over a) wheat1, b) wheat2, c) maize, d) rice, and e) meadow. Values of LAI are either

956 measured (dots), interpolated between measurements (solid line), or derived from FORMOSAT-2 data by using

957 NNT $_{\text {NDVI }}$ approach $(\mathbf{x})$. Vertical bars illustrate the $95 \%$ confidence interval around the ground based 958 measurements mean. Vertical arrows in e) represent meadow cutting dates.

959 

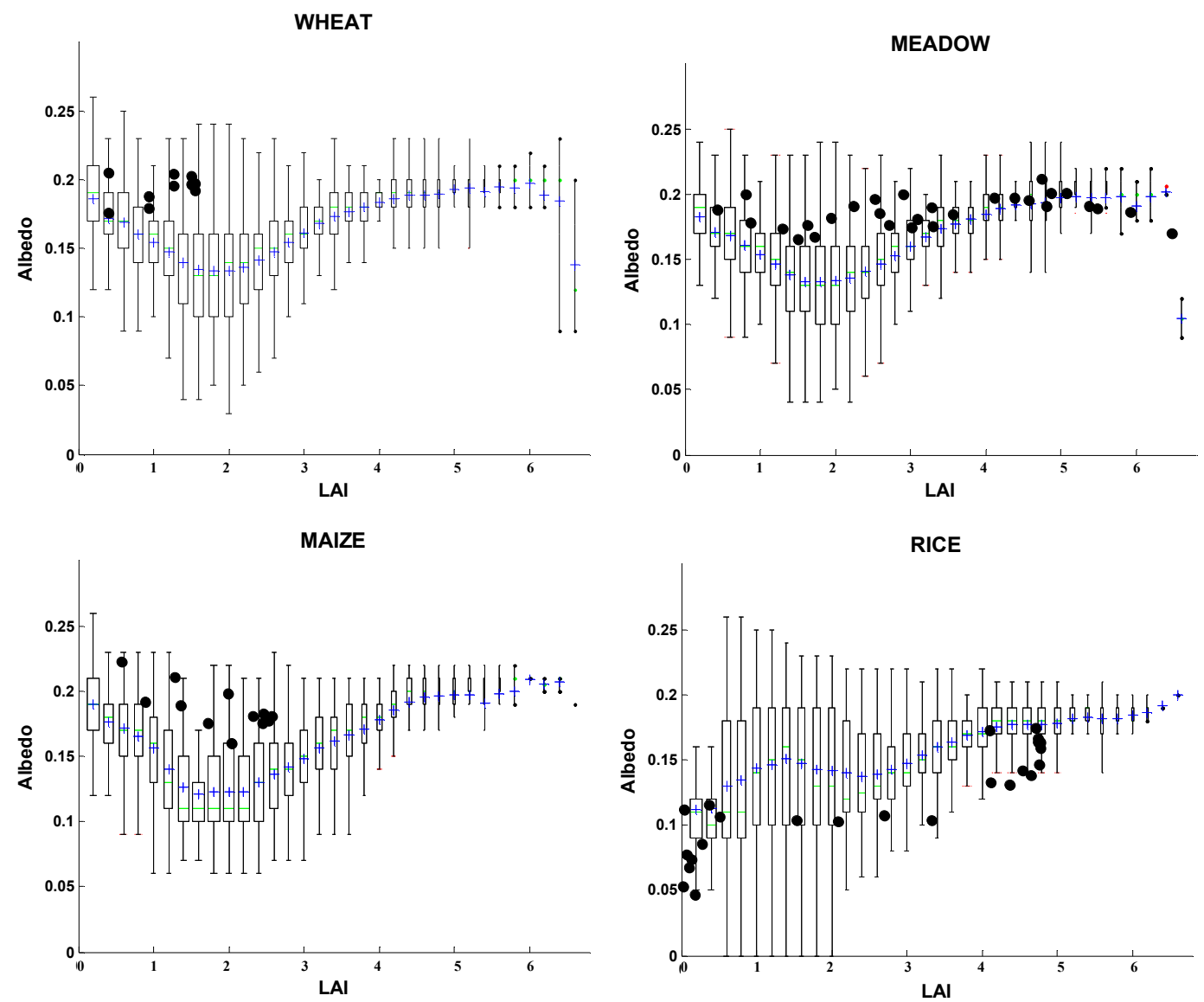

962

963

964

Figure 10: Boxplots of FORMOSAT-2 albedo retrievals as a function of FORMOSAT-2 estimated leaf area index LAI classes (0.2 LAI steps), for all available observations and for each vegetation type derived from the land use classification (section 2.1.1). (+) symbols represent the mean estimated albedo for each estimated LAI class, and (•) symbols represent albedo versus LAI measured in the field. The rectangles limit the lower and upper quartiles. The vertical bars limit the largest non-outlier observations.

969

970 


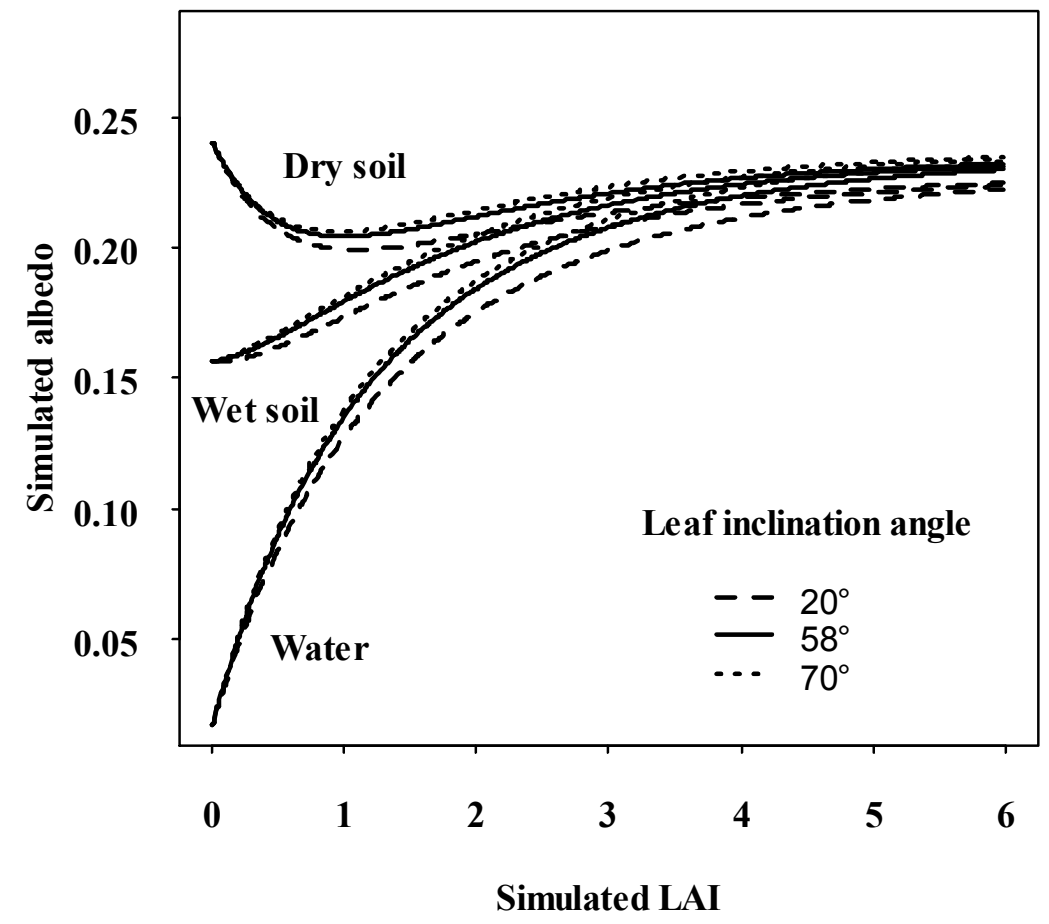

972

973

974 Figure 11: Theoretical relationship between albedo and LAI as simulated by the radiative transfer model

975 PROSAIL over three contrasted back-ground surfaces and three leaf inclination angles (Parameterization 976 details in Table 5).

977

978 
979 LIST OF TABLES

980 
982 Table 1: Overview of vegetation characteristics observed for the five study fields. Coefficient of Variation (CV) 983 was derived from FORMOSAT-2 pixels by considering the whole field (borders excluded) for LAI (LAI CV) and 984 the albedometer footprint for albedo (Albedo CV). For meadow (Field \#3), $1^{\text {st }}$ and $2^{\text {nd }}$ cycle corresponded to growth cycles after cuts. Values of LAI and albedo CV are discussed in Section 2.1.5.

986

\begin{tabular}{|c|c|c|c|c|c|c|}
\hline Studied Fields & $\begin{array}{l}\text { Field area } \\
\text { (ha) }\end{array}$ & $\begin{array}{c}\text { Period of } \\
\text { data collection }\end{array}$ & $\begin{array}{l}\text { Number of days } \\
\text { with collection } \\
\text { of ground based } \\
\text { LAI data }\end{array}$ & Maximum LAI & $\begin{array}{c}\text { LAI } \\
\text { CV }(\%)\end{array}$ & $\begin{array}{l}\text { Albedo } \\
\text { CV (\%) }\end{array}$ \\
\hline \#1 - Wheat 1 & 30 & March $10^{\text {th }}-$ May 30th & 6 & 1.55 & 1.0 & 1.5 \\
\hline \#2 - Wheat 2 & 10 & March $10^{\text {th }}-$ May 30th & 6 & 2.0 & 1.5 & 1.0 \\
\hline \#3 - Meadow & 30 & March $10^{\text {th }}-$ October $10^{\text {th }}$ & 14 & $\begin{array}{l}6.3\left(1^{\text {st }} \text { cycle }\right), \\
4.8\left(2^{\text {nd }} \text { cycle }\right)\end{array}$ & 3.6 & 1.1 \\
\hline \#4 - Maize & 2 & June $1^{\text {st }}-$ August $8^{\text {th }}$ & 5 & 2.5 & 17.1 & 2.6 \\
\hline \#5 - Rice & 4 & June $1^{\text {st }}-$ August $27^{\text {th }}$ & 5 & 4.8 & 2.1 & 1.2 \\
\hline
\end{tabular}

987 
990 Table 2: Description of datasets for albedo and LAI ground based measurements, after spatial and temporal 991 matching with FORMOSAT-2 data.

992

\begin{tabular}{|c|c|c|c|c|c|}
\hline Variable & $\begin{array}{c}\text { Ground } \\
\text { measurements }\end{array}$ & Spatial matching & Temporal matching & $\begin{array}{c}\text { Dataset } \\
\text { size }\end{array}$ & $\begin{array}{c}\text { Range of } \\
\text { values }\end{array}$ \\
\hline Albedo & Albedometer & $\begin{array}{l}\text { Measurement footprint } \\
(4 \times 4 \text { pixels })\end{array}$ & Measurements at 10:30 UT & 130 & {$\left[\begin{array}{ll}0.10 & 0.27\end{array}\right]$} \\
\hline LAI & Hemispherical images & Entire field ( $\approx 300$ pixels $)$ & $\begin{array}{c}\text { Temporal interpolation } \\
\text { using equation (1) }\end{array}$ & 97 & {$\left[\begin{array}{lll}0.00 & 6.8\end{array}\right]$} \\
\hline
\end{tabular}

993

994 
996 Table 3: Models and variables used for simulating of albedo and LAI. Values corresponded to typical average 997 soil and vegetation characteristics representative of our experimental conditions.

998

\begin{tabular}{ll}
\hline MODELS \& Variables & Values \\
\hline \hline PROSPECT (Leaf optical characteristics) & \\
Chlorophyll content & $60 \mu \mathrm{g} / \mathrm{cm}^{2}$ \\
Dry matter & 0.0075 \\
Relative water content & $80 \%$ \\
Mesophyll structure parameter & 1.2 \\
Simulation spectrum & 300 to $2400 \mathrm{~nm}$ \\
& \\
SAIL (radiative model) & $30^{\circ}$ \\
Zenith angle & Derived from $6 \mathrm{~S}$ (See below) \\
Diffuse fraction & 0.01 \\
Hot spot parameter & $20^{\circ}, 58^{\circ}$ and $70^{\circ}$ with ellipsoidal distribution \\
Leaf inclination angles & 0 to 6 (Step $=0.2$ ) \\
LAI values & Water, wet soil, dry soil \\
Soil background & \\
6S (radiative transfer model) & \\
Aerosol model & Continental \\
Aerosol optical thickness & 0.2347 at 550 nm \\
Environmental reflectance & Equal to the reflectance of the target \\
\hline
\end{tabular}

999 
1002 Table 4: Coefficients sets used to compute albedo as a linear combination of waveband FORMOSAT-2 1003 reflectances. Set 1 and NNT were calibrated over the Crau-Camargue dataset using FORMOSAT-2 off nadir 1004 bidirectional reflectances. Sets 2 and 3 were designed for generic spectral configurations, and calibrated over 1005 simulated data set by considering hemispherical reflectances. Set 4 was devoted to the PolDER derived 1006 hemispherical reflectances, and calibrated over the Alpilles-Reseda measured dataset. Set 5 was devoted to the

1007 MISR sensor, and calibrated over a simulated dataset by considering nadir bidirectional reflectances. The 1008 waveband limits (in $\mathbf{n m}$ ) considered for each coefficient set are reported. Are also indicated the sum of

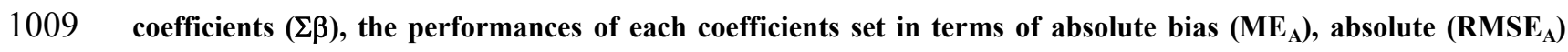
1010 and relative $\left(\mathrm{RMSE}_{\mathrm{R}}\right)$ root mean square errors. The last column corresponds to the number of coefficients to be 1011 adjusted in each empirical model.

1012

\begin{tabular}{cccccccccc}
\hline & Green & Red & NIR & $\beta_{\mathbf{0}}$ & $\Sigma \beta$ & ME $_{\mathbf{A}}$ & RMSE & RMSE & $\begin{array}{c}\text { Freedom } \\
\text { degree }\end{array}$ \\
\hline \hline FORMOSAT & $\mathbf{5 2 0 - 6 0 0}$ & $\mathbf{6 3 0 - 6 9 0}$ & $\mathbf{7 6 0 - 9 0 0}$ & & & & & & \\
Set 1 & 0.000 & 0.619 & 0.402 & 0.000 & 1.021 & 0.000 & 0.015 & $7.3 \%$ & 3 \\
NNT & - & - & - & - & & 0.000 & 0.007 & $3.5 \%$ & 11 \\
Weiss et al. (1999) & $\mathbf{5 6 0}$ & $\mathbf{6 6 5}$ & $\mathbf{8 5 5}$ & & & & & & \\
Set 2 & 0.000 & 0.570 & 0.460 & 0.000 & 1.030 & -0.012 & 0.019 & $9.7 \%$ & 2 \\
Set 3 & 0.680 & 0.080 & 0.350 & 0.000 & 1.110 & 0.021 & 0.029 & $14.2 \%$ & 3 \\
Jacob et al. (2002a) & $\mathbf{5 3 0 - 5 7 0}$ & $\mathbf{6 5 0 - 6 9 0}$ & $\mathbf{8 4 5 - 8 8 5}$ & & & & & & \\
Set 4 & 0.000 & 0.591 & 0.374 & -0.001 & 0.965 & 0.014 & 0.020 & $9.7 \%$ & 3 \\
Liang et al.(1999) & $\mathbf{5 4 4 - 5 7 1}$ & $\mathbf{6 6 2 - 6 8 2}$ & $\mathbf{8 4 7 - 8 8 6}$ & & & & & & 4 \\
Set 5 & 0.126 & 0.343 & 0.415 & 0.004 & 0.884 & 0.018 & 0.027 & $13.4 \%$ \\
\hline
\end{tabular}

1013

1014 
1016 Table 5: Obtained parameters when calibrating the various empirical methods we considered for the retrieval of

1017 LAI from FORMOSAT-2 data. Are also indicated the performances of each method in terms of absolute bias

$1018\left(M_{A}\right)$, absolute $\left(R_{M S E}\right)$ and relative $\left(R_{M S E}\right)$ root mean square errors. The last column corresponds to the

1019 number of coefficients to be adjusted in each empirical model. First is the multiple linear regression over

1020 FORMOSAT-2 reflectances. Second is the NNT based method that uses as inputs FORMOSAT-2 reflectances.

1021 Third is the heuristic formulation of LAI as a function of NDVI. Fourth and last is the NNT based method that 1022 uses as input FORMOSAT-2 NDVI.

1023

\begin{tabular}{|c|c|c|c|c|c|c|c|c|c|c|}
\hline Coefficients & Red & NIR & $\beta_{0}$ & $\mathbf{K}_{\mathrm{LAI}}$ & $\mathbf{N D V I}_{\infty}$ & $\mathrm{NDVI}_{\mathrm{s}}$ & $\mathbf{M E}_{\mathrm{A}}$ & $\mathbf{R M S E}_{\mathrm{A}}$ & $\mathrm{RMSE}_{\mathrm{R}}(\%)$ & $\begin{array}{c}\text { Freedom } \\
\text { degree }\end{array}$ \\
\hline Multiple regression & -17.91 & 12.26 & 0 & 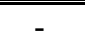 & - & - & 0.03 & 1.29 & 64.58 & 3 \\
\hline $\mathbf{N N T}_{\text {Ref }}$ & - & - & - & - & - & - & -0.03 & 0.69 & 34.63 & 11 \\
\hline NDVI based method & - & - & - & 0.71 & 0.89 & 0.10 & 0.05 & 0.66 & 33.37 & 3 \\
\hline $\mathbf{N N T}_{\text {NDVI }}$ & - & - & - & - & - & - & 0.02 & 0.55 & 27.54 & 7 \\
\hline
\end{tabular}

